\title{
المساهمة المالية للزوجة وأثره على دورها داخل الأسرة
}

\author{
إعـــــلداد \\ ه / إيمان شعبار أحمد \\ مدرس إدارة المنزل والمؤسسات بقسم الاقتصاد المنزلي \\ كلية التربية النوعية - جامعة بنها
}

مجلة بحوث التربية النوعية - جامعة المنصورة

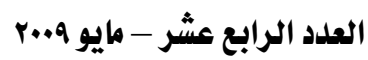




\section{المستاهمة المالية للزوجة وأثره على دورها داخل الأسرة}

$$
\text { إعــداد }
$$
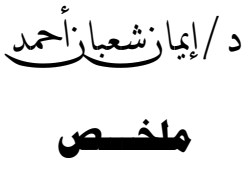

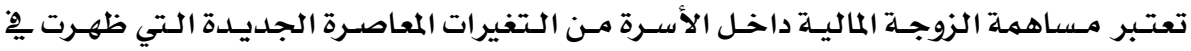

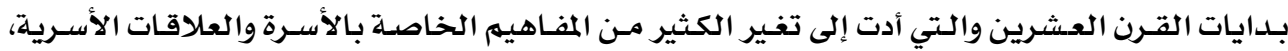

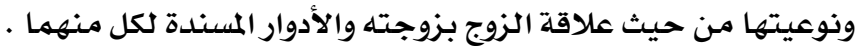

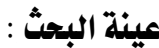

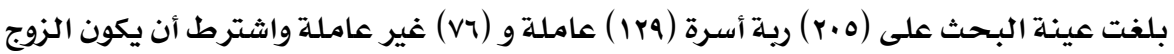

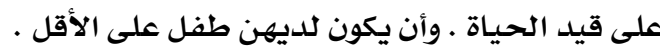

اشتملت أدوات البحث على استمارة البيانات العامـة للأسرة ، استبيان المساهمـة المالية للزوجـة ،

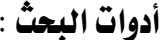

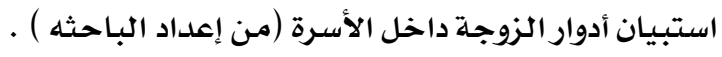

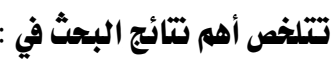

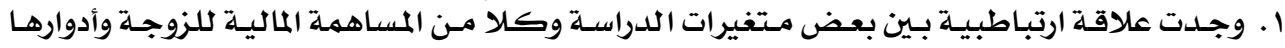

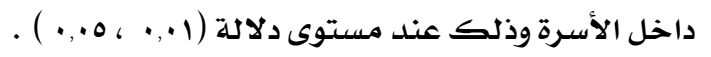

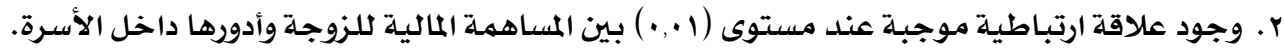

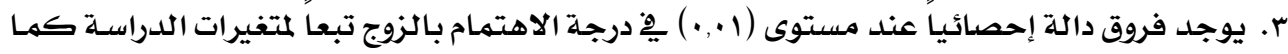

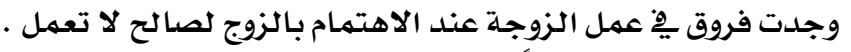

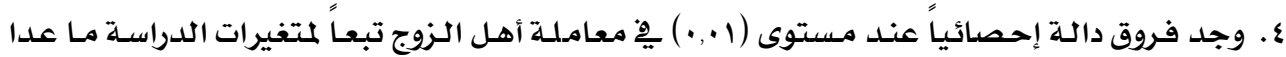

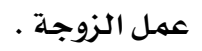

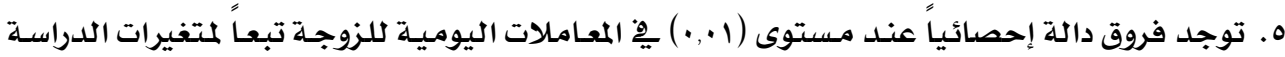

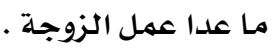

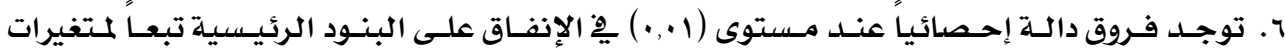

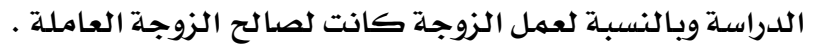

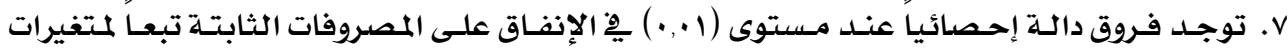

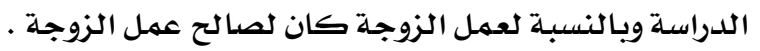

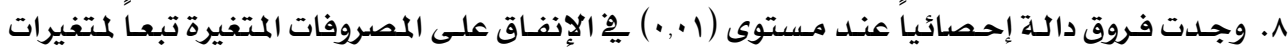

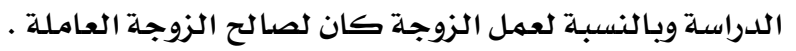




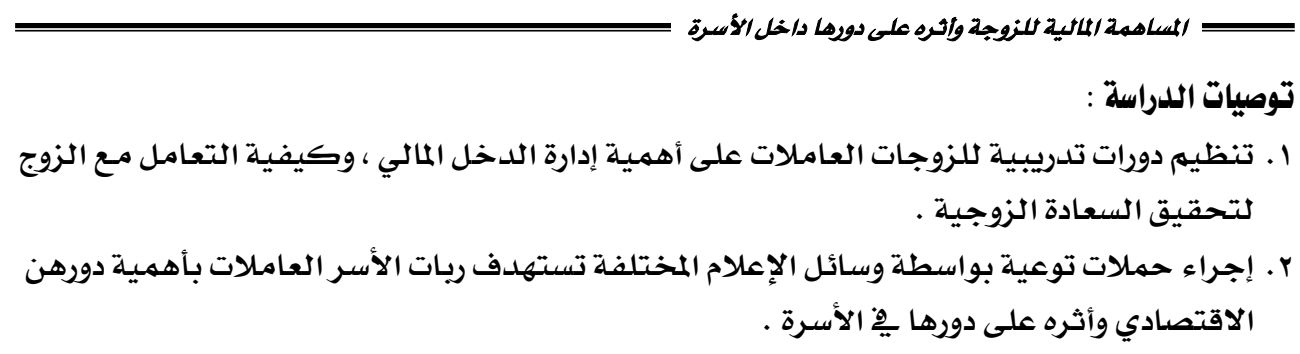

Summary

The wife Financial Contribution and its Effect on her Role in the Family Dr| Eman Shaban Ahmed

Professor of house and institutions management Specific Education College- Banha University

The wife Financial Contribution in the family is considered one of modern changes that appeared at the beginning of the twentieth century that led to changes of family concepts and relationships, husband wife relationship and every one role.

\section{Community:}

The sample consisted of ( 205) house wives, ( 129) working, ( 76) non working women who have alive husbands and one child at least .

\section{Tools:}

Included the family general application form, wife financial contribution questionnaire, wife role in the family ( a questionnaire prepared by the researcher) .

\section{The Research Results are:}

1. There is a correlation between some variables, both the wife financial contribution in the family and her roles in the family at the significance level( .01, .05).

2. There is a positive correlation at the level (.01) between The wife financial contribution and her roles in the family.

3. There are statistically significant differences at the level ( .01) in caring about husband according to the study variables, there were differences in wife work at caring about husband for the non working interest.

4. There are statistically significant differences at the level (.01) in husband relatives treatment according to the study variables except the wife work.

5. There are statistically significant differences at the level (.01) in daily treatments according to the study variables except the wife work. 
6. There are statistically significant differences at the level (.01) in expenses for main items according to the study variables, they were for the interest of working wife.

7. There are statistically significant differences at the level (.01) in expenses for the constant items according to the study variables, they were for the interest of working wife.

8. There are statistically significant differences at the level (.01) in expenses for the changed items according to the study variables, they were for the interest of working wife.

\section{The Recommendations:}

1. Organization of training courses for working wives about the financial income management, how to treat husbands to achieve happy life.

2. Preparation of educating media onsets about the working wives economical role and its effect on their role in the family. 


\section{المساهمة المالية للزوجة وأثره على دورها داخل الأسرة}

$$
\text { إعـــداد }
$$

د /إيمازشعبانزحمد

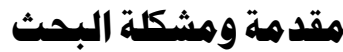

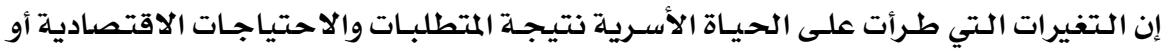

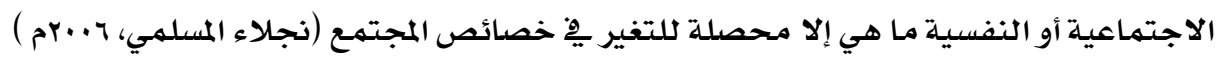

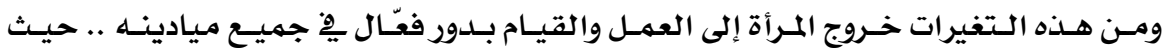

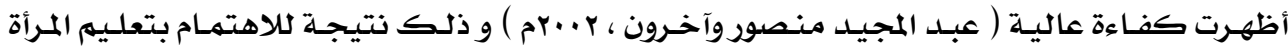

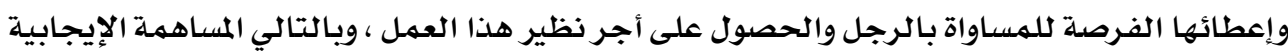

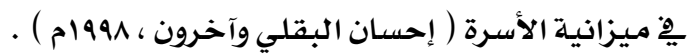

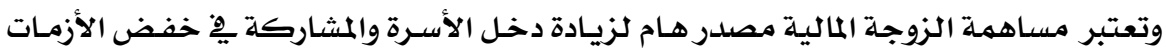

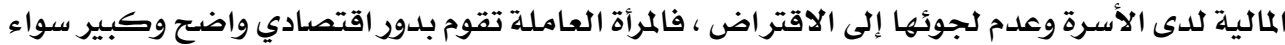

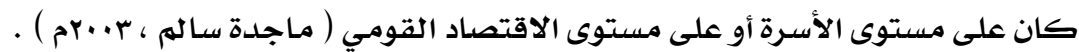

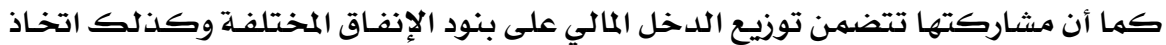

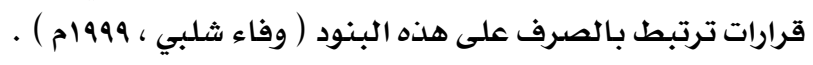

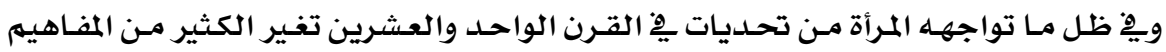

الخاصة بالأسرة والعلاقات الأسرية ونوعيتها من حيث علاقة المرات الزوج بزوجته الأدوار المسندة لكل منهما

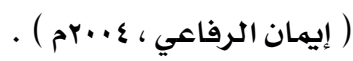

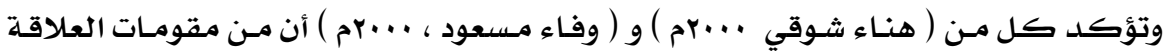

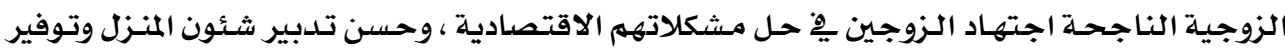

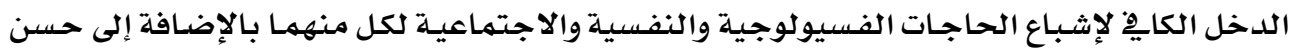

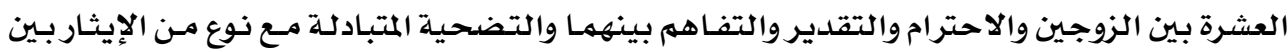

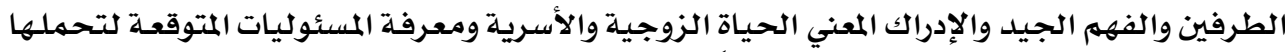

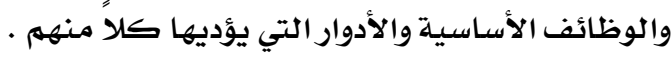
وتتضح مشكلة البحث يِّ الإجابة على التساؤلات التالية :

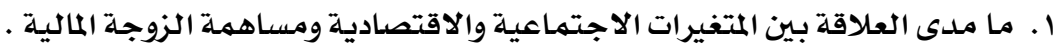

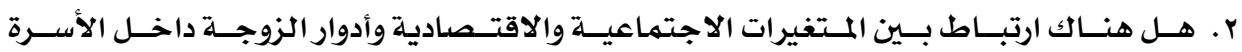

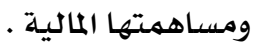
r. مـ الارتباط بين مساهمة الزوجة المالية وأدوارها داخل الأسرة . 
ع. مـا ترتيب أولويات المتغيرات الاجتماعية والاقتصادية على مسـاهمة الزوجـة المالية .

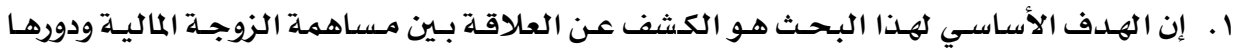

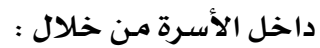

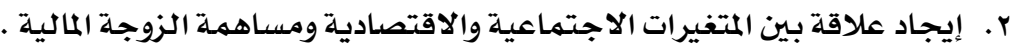

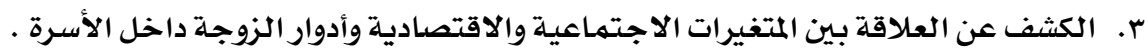

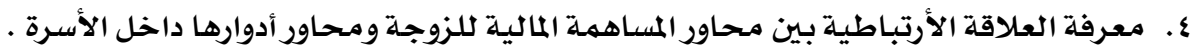

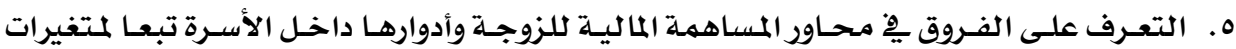
الدراسـة. ج. تحديد نسبـة مشاركة متتغيرات المستوى الاجتماعي والاقتصادي على المساهمة المالية للزوجة.

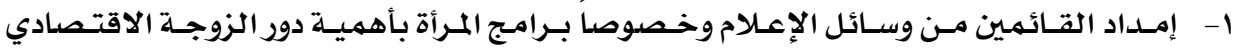

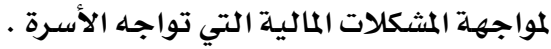

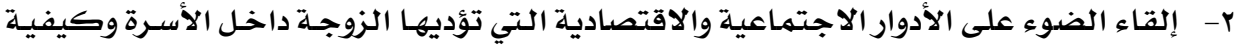
أدائها بطريقة سليمـة لنصل إلى أسرة مستقرة مترابطة .

\section{الأسلوب البحث : \\ أولاً : نروض الدراسة :}

ا. توجد علاقة ارتباطية بين متغيرات الدراسـة ومحاور أدوار الزوجـة ومحاور المسـاهمة المالية. r. توجد علاقة ارتباطية بين محاور المساهمـة المالية وأدوار الزوجة داخل الأسرة . r. توجد فروق دالة إحصائياً بين أفراد عينة البـحث يِّ درجة الاهتمام بالزوج تبعاً لمتغيرات الدراسـة

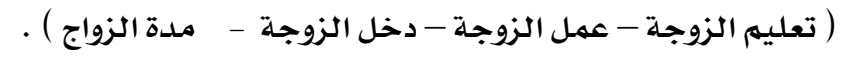

ع. توجد فروق دالـة إحصائيـاً بـين أفراد عينـة البحث ِِّ معاملـة أهل الـزوج تبعـاً لمتغيرات الدراسـة

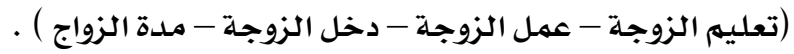

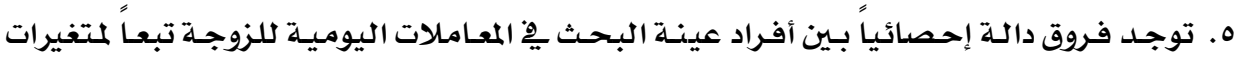

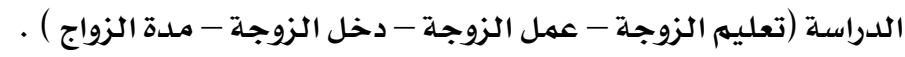

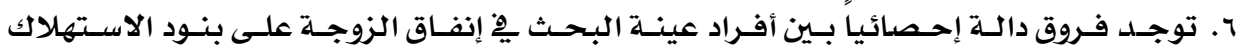

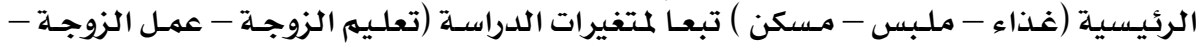

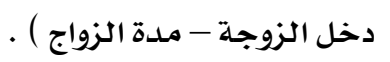

V. توجد فروق دالة إحصائياً بين أفراد عينـة البـحث يْ إنفاق الزوجـة على المصروفات الثابتـة تبعـاً

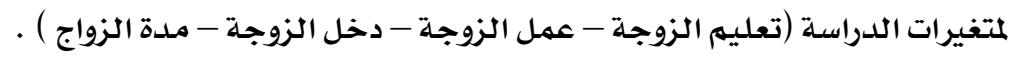




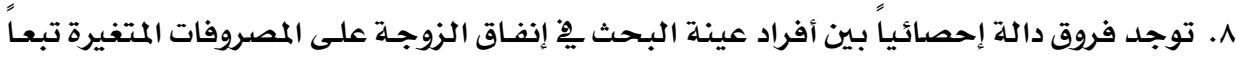

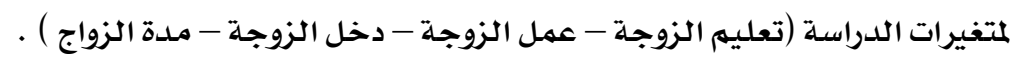

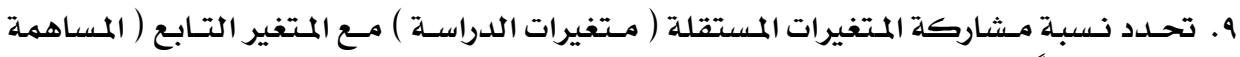

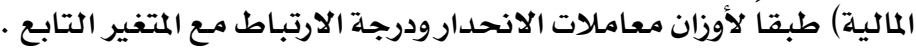

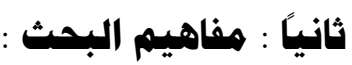

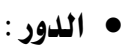

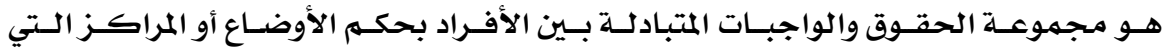

يشغلونها يِّ بناء اجتماعي معين ( زينب حقي ، 1991ام ) .

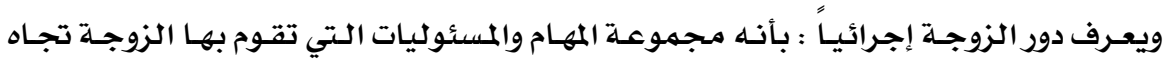

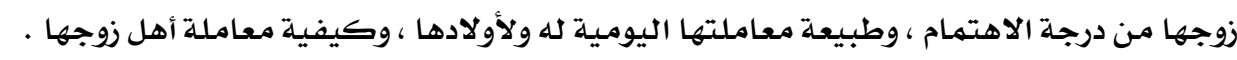

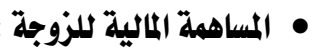

هي مـدى المساهمة على بنـود الإنفـاق الخاصـة بميزانيـة الأسـرة بهـدف الانتفـاع مـن الموارد

$$
\begin{aligned}
& \text { بأقصى منفعة ممكنة وِِّ فترة زمنية محددة . } \\
& \text { منهج البحث : بافئ منفة } \\
& \text { يتبع هذا البحث المنهج الوصفي التحليلي . }
\end{aligned}
$$

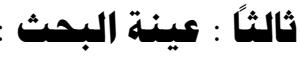

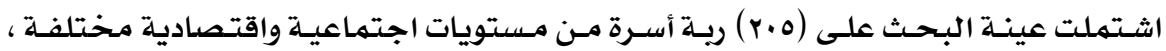

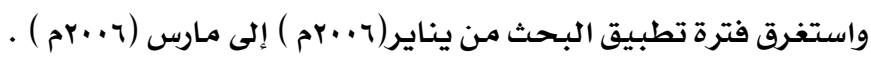

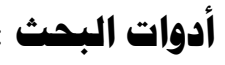

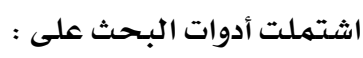

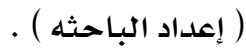

$$
\begin{aligned}
& \text { 1. استمارة البيانات العامة للأسرة }
\end{aligned}
$$

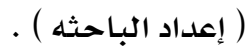

$$
\begin{aligned}
& \text { r r استبيان المساهمة المالية }
\end{aligned}
$$

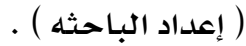

$$
\begin{aligned}
& \text { r. استبيان أدوار الزوجة الزها }
\end{aligned}
$$

ا - استـهارة البيانات العاهة :

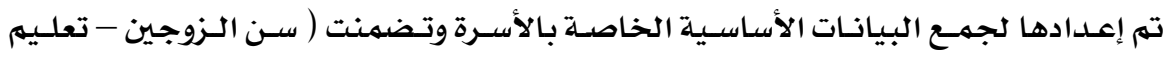
الزوجين - مهنة الزوجين - دخل الزوجين - مدة الزواج - عدد الأبناء ) . 
وهو عبارة عن ثلاثة محاور :

• المحور الأول: الإنفاق على بنود الاستهلاك الرئيسية (غذاء - ملبس - مسكن ) ، وهو عبارة عن

. (9) عبارات (1)

• المحور الثاني : تضمن الإنفاق على المصروفات الثابتة وتكون من (؟) عبارات .

• المحور الثالث : الإنفاق على بنود الاستهالك المتغيرة وتكون من (v) عبارات .

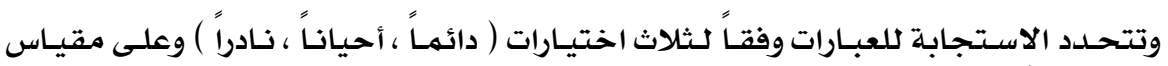

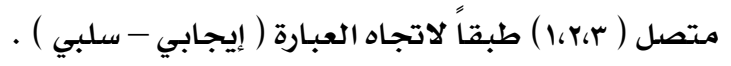

صدق الاقياس :

للتأكـد مـن صـدق الاسـتبيان تم حسـاب صـدق الاتسـاق الـداخلي عن طريـق حسـاب معامـل

الارتباط بين كل محوروالمجموع الكلي للمحاور ، ويتبـين هذا من جدول (1) (1) .

جدول (1) قيم معاملات ارتباط بين درجات كل محوروالدرجة الكلية

\begin{tabular}{|c|c|c|}
\hline الدلادلة & الارتباط & المحاور \\
\hline$\cdot, \cdot 1$ & $\cdot, \wedge \vee r$ & الإنفاق على بنود الاستهلالك الرئيسية \\
\hline$\cdot, \cdot 1$ & $\cdot, \wedge 1 \varepsilon$ & الإنفاق على المصروفات الثابتة \\
\hline$\cdot, \cdot 1$ & דra & الإنفاق على المصروفات المتغيرة \\
\hline
\end{tabular}

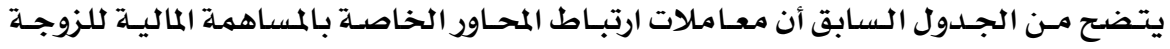

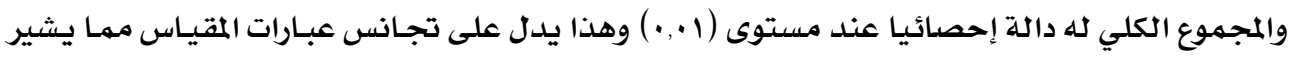

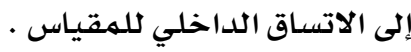

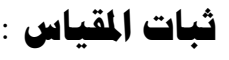

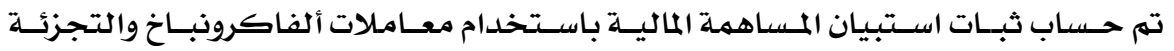

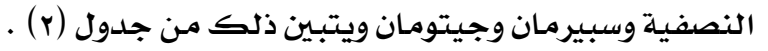

جدول (r) معاملات ارتباط الثبات لاستبيان المساهمة المالية

\begin{tabular}{|c|c|c|c|c|c|}
\hline مستوى الدلالة & جيوتمان & سبيرمان & التجزئة النصفية & معامل ألفـا & المحاور \\
\hline$\cdot . \cdot 1$ & $\cdot, V Y I$ &., 917 & $\cdot, \wedge \Sigma 7$ & $\cdot, V \leqslant 7$ & المصرفات الرئيسية \\
\hline$\cdot . \cdot 1$ & .940 & $\cdot 9 \mathrm{Vr}$ & $\cdot 9 \leqslant \wedge$ & $\cdot 9 \xi$. & المصرفات الثابتة \\
\hline$\cdot . \cdot 1$ & $\cdot, v \cdot r$ & $\cdot 91 \mathrm{r}$ & $\cdot, \wedge r q$ & $\cdot, \mathrm{vr}$. & المصروفات المتغيرة \\
\hline$\cdot, \cdot 1$ & $\cdot, \mathrm{V} 91$ & ( ) & $\cdot \wedge \mathrm{NV}$ & $\cdot, \wedge 17$ & إجمال المسـاهمة \\
\hline
\end{tabular}




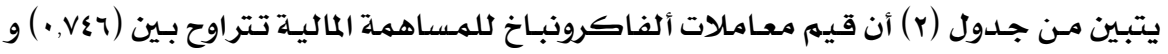

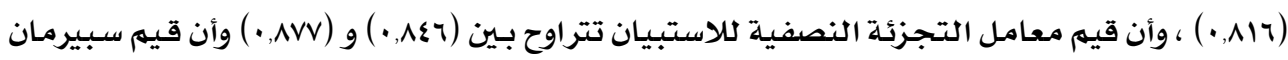

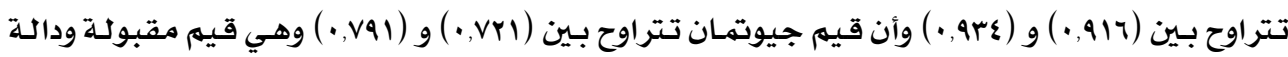

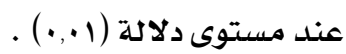

\section{r- استبيان دور الزوجة داخل الأسرة}

أعد هذا الاستبيان ِِّ ضوء الإطار النظري والدراسات السابقة ويتكون من ثلاث محاور .

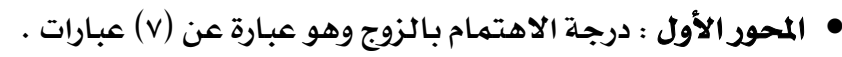

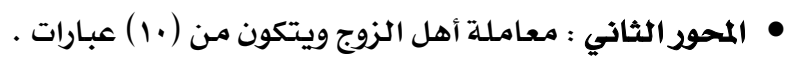

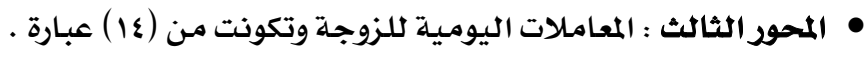

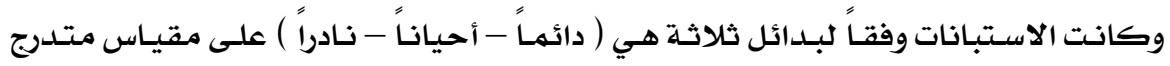

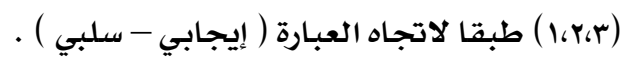

صدق الاستبيان :

للتأكد مـن صـدق الاستبيان تم حساب صـدق الاتساق الداخلي عن طريق حساب معامل

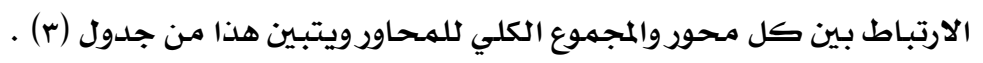

جدول (r) (r)

قيم معاملات ارتباط لاستبيان أدوار الزوجة

\begin{tabular}{|c|c|c|}
\hline الدلادلة & الارتباط & المحاور \\
\hline$\cdot, \cdot 1$ & $\cdot, \wedge \circ \mathrm{V}$ & الاهتمام بالزوج \\
\hline$\cdot, \cdot 1$ & - & معاملـة أهل الزوج \\
\hline$\cdot ., 1$ & $\cdot, \mathrm{V} 91$ & المعاملات اليومية \\
\hline
\end{tabular}

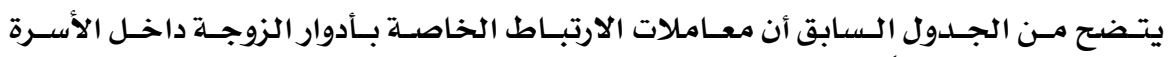

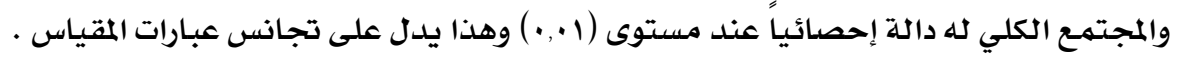

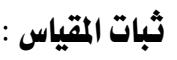

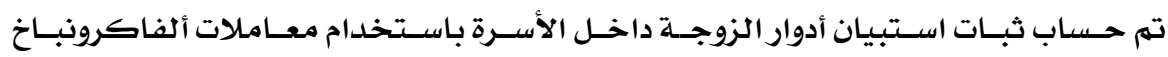

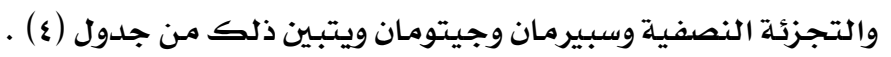


جدول (ع)

معاملات ارتباط الثبات لاستبيان أدوار الزوجة إنة

\begin{tabular}{|c|c|c|c|c|c|}
\hline مستوى الدلادة & جيوتمان & سبيرمان & التجزئة النصفية & معامل ألفا & المحاور \\
\hline$\cdot, \cdot 1$ & $\cdot, \mathrm{VVr}$ & $\cdot .9 Y 9$ & $\cdot, 179$ & $\cdot, \mathrm{V} 91$ & الاهتمام بالزوج \\
\hline$\cdot, \cdot 1$ & $\cdot, \wedge r q$ & $\cdot, 9 \leq \varepsilon$ & $\cdot, \wedge 90$ & $\cdot, \wedge \circ \mathrm{r}$ & معامـل أهل الزوج \\
\hline$\cdot ., 1$ & •, V०\& & $\cdot .9 Y 0$ & $\cdot, \wedge 71$ & $\cdot, \mathrm{VA}$. & المعاملات اليومية \\
\hline$\cdot .+1$ & $\cdot, \Lambda \cdot r$ & $\cdot, 949$ & •,AMr & • & إجمالى الأدوار \\
\hline
\end{tabular}

اتضح من جلدول ( ع) أن قيم معاملات الفاكرونباخ والتجزئة النصفية وسببيرمان وجيوتمـان

جميع قيمهم دالة ومقبولة عند مستوى (1 (-. • ) .

نتائج الدراسة وهناقشتها

( أ ) ت ائج وصف العينة :

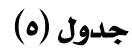

توزيـع أفراد العينة تبعاً لمستوى تعليم الزوجة (ه

\begin{tabular}{|c|c|c|}
\hline النسبـة المئويـة & العلدد & تعليهم الزوجة \\
\hline$\%, r V, r$ & 07 & منـخفض \\
\hline$\% \mu r, V$ & TV & متوسط \\
\hline$\%$. & $\Delta r$ & عاد \\
\hline
\end{tabular}

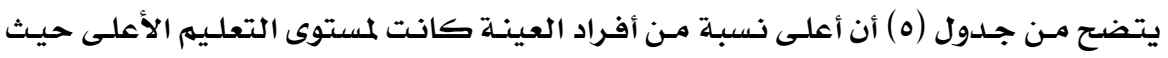

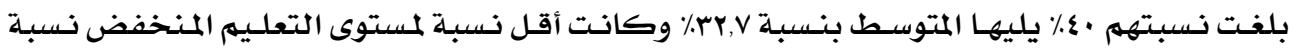
. $\% \mathrm{rV}, \mathrm{r}$

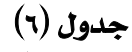

توزيع أفراد العينة تبعاً لعمل الزوجة (1)

\begin{tabular}{|c|c|c|}
\hline النسبة المئويـة & العدد & عمل الزوجـة \\
\hline r & $1 r q$ & تعمل \\
\hline$\% r V$ & V7 & لا تعمل \\
\hline$\% 1 \ldots$ & $r .0$ & محمووع \\
\hline
\end{tabular}

يتبين من جدول (7) أن سج٪ من الزوجات تعمل بينما Vr٪ لا يعمل . 
جدول (v)

توزيـع أفراد العينة تبعاً لمستوى مهنة الزوجة

\begin{tabular}{|c|c|c|}
\hline النسبـة المئويـة & العددد & مستوى المهن \\
\hline$\%, Y 0,0$ & r & مهن منخفضلة المستوى \\
\hline r & $\varepsilon$. & مهن متوسطة المستوى \\
\hline$\varepsilon r, 0$ & 07 & مهن عليا \\
\hline$\% 1 \ldots$ & $1 r q$ & مجموع \\
\hline
\end{tabular}

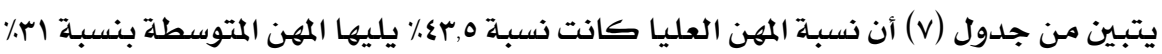

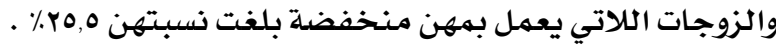

$$
\text { جلدول (^) }
$$

توزيـع أفراد العينة تبعاً لدخل الزوجة

\begin{tabular}{|c|c|c|}
\hline النسبـة المئئويـة & العدد & دخل الزوجة \\
\hline$\%, Y \wedge, \vee$ & rv & منخفضشة الدخل \\
\hline$\%<\varepsilon, 1$ & $\varepsilon \varepsilon$ & متوسطة الدخل \\
\hline$\% r v, r$ & $\varepsilon \wedge$ & مـرتفعـة الدخل \\
\hline$\% 1 \ldots$ & $1 \times 9$ & المجموع \\
\hline
\end{tabular}

يتبين من جدول (^) أن أعلى نسبة كانت للدخل المرتفع بنسبة r.rV. . . .

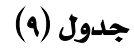

توزيع أفراد العينة تبعاً لمدة الزواج

\begin{tabular}{|c|c|c|}
\hline النسبــة المئويـة & العددد & مدة الزواج \\
\hline$\%$ YY, & $\varepsilon 7$ & مدة صغيرة \\
\hline$\%$ \%, 1 & VY & مدة متوسطة \\
\hline$\% \varepsilon r, 0$ & $\Lambda \vee$ & مدة كبيرة \\
\hline$\% 1 \ldots$ & $r .0$ & مجمبوع \\
\hline
\end{tabular}

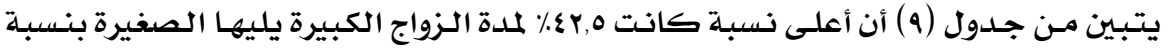

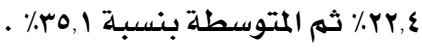




\section{( ب ) فروض البحث : \\ • الفرض الأول :}

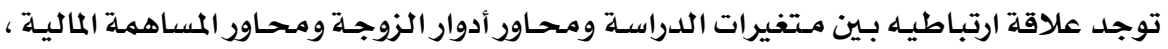

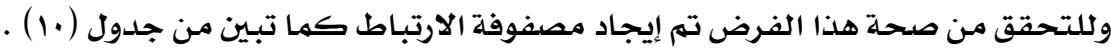

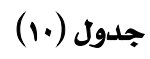

مصفوفة معاملات الارتباط بين متغيرات الدراسة ومحاور المساهمة المالية وأدوار الزوجة داخل الأسرة

\begin{tabular}{|c|c|c|c|c|c|c|c|c|}
\hline إجمالي & المتلغروفات & المصروفات الثابتة & البنود الإنفاق على & إجمالي & |المعاملات & | معاملة أهل الزوج & الاهتمام & المحاور \\
\hline$* * \cdot, v \cdot 1$ & $* * \cdot, \backslash \Lambda \varepsilon$ & $* \cdot \pi / r$ & $* * \cdot V Y Y$ & $\% * \cdot, \wedge 9 \vee$ & $* * \cdot$ vTV & $* * \cdot v \varepsilon r$ & $\% * \cdot, 119$ & تعليم الزوجة \\
\hline$* * \cdot, \cdot v$ & $* \cdot$ AMr & $\% * \cdot, \mathrm{V7T}$ & $* * \cdot \wedge r \varepsilon$ & $* * \cdot \mathrm{VMM}$ & $* * \cdot \wedge ৭$ Y & $* * \cdot, \mathrm{vV} \varepsilon$ & $* * \cdot$, sor & تعليم الزوج \\
\hline$* * \cdot$, v79 & $* * \cdot 91 \mathrm{~V}$ & $* * \cdot, V \mid \varepsilon$ & $* * \cdot, \cdot 1$ & 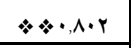 & $* * \cdot q \cdot \varepsilon$ & $* * \cdot v \cdot \Lambda$ & $* * \cdot \wedge \wedge$ ४ & مهنـة الزوجة | \\
\hline$* * \cdot, \wedge 1$ & $* * \cdot, \wedge \uparrow q$ & $* * \cdot, \cdot r$ & $* * \cdot, 9 Y \varepsilon$ & $* * \cdot, 9 Y \Lambda$ & $* *, \mathrm{vIV}$ & $* * \cdot \wedge T \varepsilon$ & 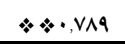 & مهنة الزوج \\
\hline$\cdot, I \leqslant r$ &., 1.4 & . rov &., $17 \varepsilon$ & $\otimes \cdot \pi r \varepsilon$ & $* \cdot, \pi \leqslant r$ & $* * \cdot \wedge \varepsilon r$ & וTוT) & سن الزوجـة \\
\hline$\$ \cdot T I V$ & $* * \cdot \Lambda \mathrm{AV}$ & $* * \cdot T \Lambda Y$ & ט. • & . 1111 &., 111 & $\cdot, I v \varepsilon$ & $\cdot r \cdot r$ & سن الزوج \\
\hline$* \cdot, \tau \leq \varepsilon$ & $* * \cdot$ ATV & $\% \cdot, 7 r 9$ & $\% * \cdot, V \mathrm{VI}$ & $* \cdot T Y \varepsilon$ & $* * \cdot$ TVY & $* \cdot 7 \cdot 1$ & * A & مدة الزواج \\
\hline$* * \cdot$ VYV & $* * \cdot, \wedge 9$ & $* * \cdot 91 r$ & 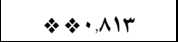 & $* \cdot, 7 \cdot 0 \quad-$ & $\star \cdot, \pi) \varepsilon$ & $\cdot r \cdot \varepsilon$ & $\% * \cdot$ vor & دخل الزوجة \\
\hline$* * \cdot \mathrm{V} \backslash \mathrm{A}$ & $* * \cdot$ VAT & $* * \cdot v v \varepsilon$ & $* * \cdot, \mathrm{rr}$ & •,YYT &., 1.1 & . $1 \wedge \varepsilon$ & .194 & دخل الزوج \\
\hline$* * \cdot$, Aor & $* * \cdot \vee \Gamma \wedge$ & $* * \cdot, 9 Y 4-$ & $* * \cdot$ AYI - & $*$, * - & $\% \cdot \pi Y V$ & - Irr & $\leftrightarrow \cdot, \cdot \xi$ & عدد الأبناء \\
\hline
\end{tabular}

يتضـح من جدول ( • ) وجود علاقـة ارتباطيـه موجبـة بـين تعلسيم الزوجـة وأدوار الزوجـة داخلل

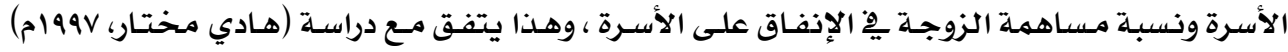

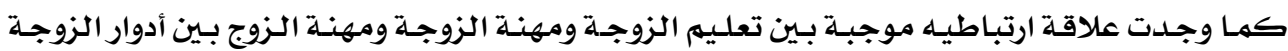

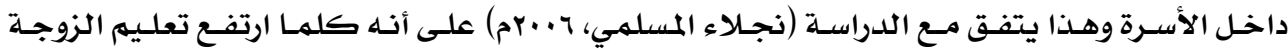

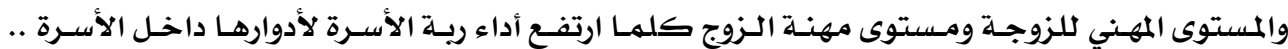
ومساهمتها المالية عند مستوى دلادية (1. (•)

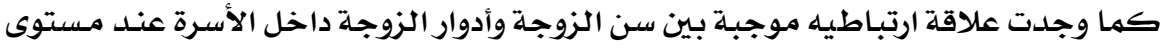

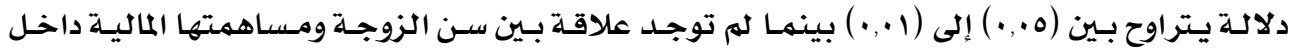

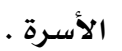

ووجدت علاقة ارتبـاطيه موجبة بين سن الزوج ومسـاهمة الزوجـة الماليـة داخل الأسـرة وذلك الكا

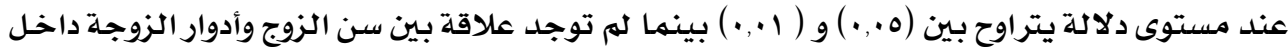




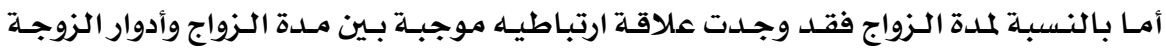

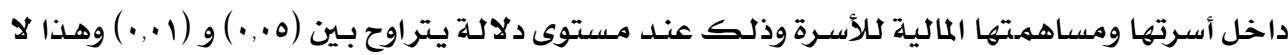

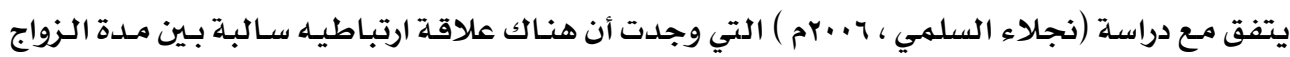

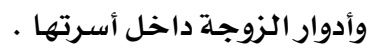

ووجدت علاقة ارتباطيه موجبة بين دخل الزوجـة وأدوارهـا داخل الأسـرة مـا عدا معاملـة أهل

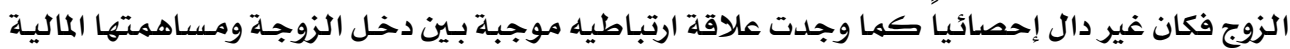

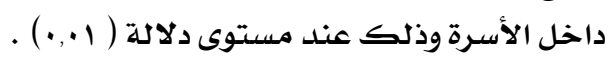

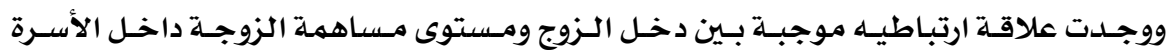

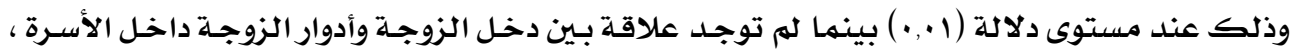

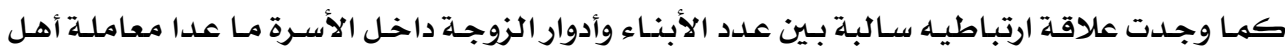

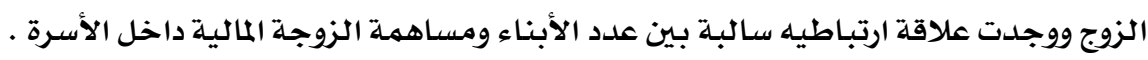

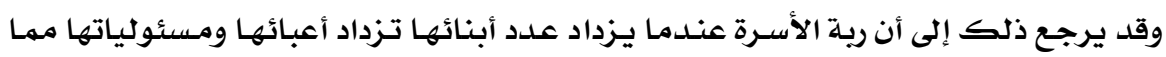

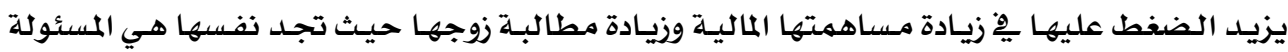

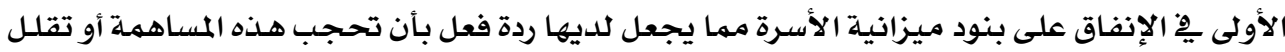

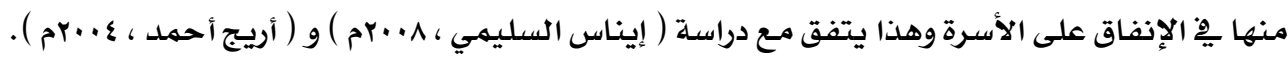

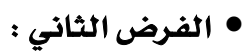

توجد علاقة ارتباطيه بين محاور المساهمة المالية وأدوار الزوجة داخل الأسرة .

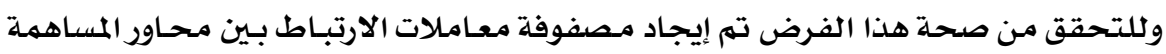

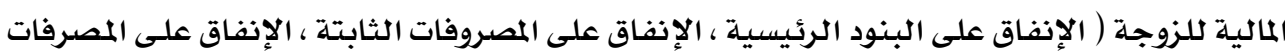

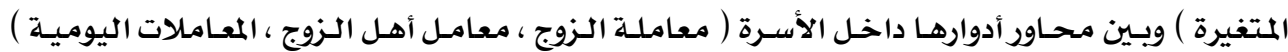

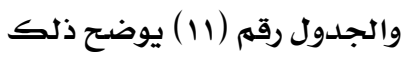

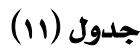

مصفوفة معاملات الارتباط بين متغيرات الدراسة ومحاور المساهمة المالية وأدوار الزوجة داخل الأسرة

\begin{tabular}{|c|c|c|c|c|}
\hline الاستجابة & المصروفات & المصروفات الثابتة & البنود الإنفاق على الريسية & \\
\hline$* * \cdot v \cdot 9$ & $* *, \wedge 0 \wedge$ & $* *, \times 19$ & $* * \cdot, \cdot, 7$ & الاهتمام بالزوج \\
\hline$* \cdot, \wedge \varepsilon 7$ & $* \cdot \mathrm{V} \wedge \mathrm{V}$ & $* * \cdot 9 \cdot r$ & ד & معاملة أهل الزوج \\
\hline$\$ .910$ & $* *, \Lambda \wedge r$ & $* * \cdot, \cdot r$ & $* * \cdot 941$ & المعاملات اليومية \\
\hline$* *, \wedge \cdot 0$ & $* *, \wedge 1 \wedge$ & $* *, \mathrm{VV \Lambda}$ & $* *, \wedge r V$ & الاستمارة ككل \\
\hline
\end{tabular}

يتبين مـن الجدول (11) أن هناك علاقة ارتباطيه موجبـة الاهتمـام بالزوجـة ومسـاهمة الزوجـة

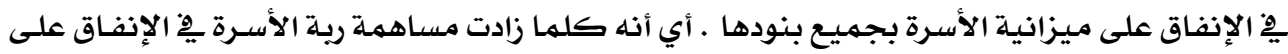




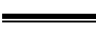
مجلة بحوث التربية النوعية - العلدد الرابع عشر- مايو و...

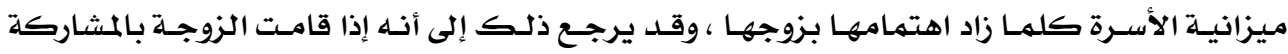

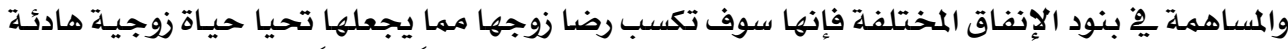

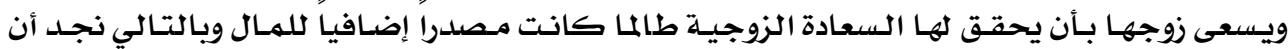

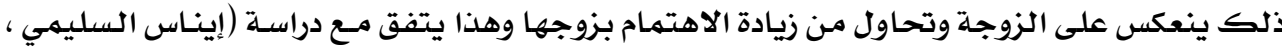
$\cdot($ ar..人

كما وجدات علاقة ارتباطيه موجبة بين محاور مسـاهمـة الزوجـة على بنـود الإنفـاق المختلفـة

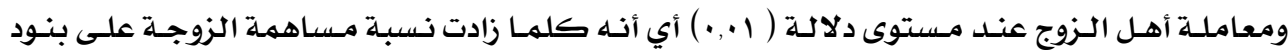
الإنفاق الرئيسية كلما كانت معاملتها لأهل زوجها أفضل .

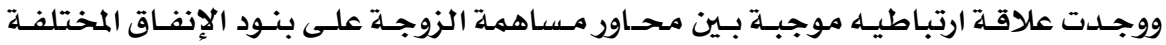

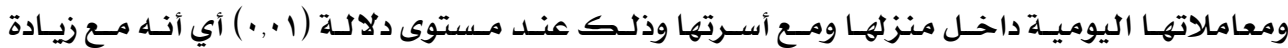

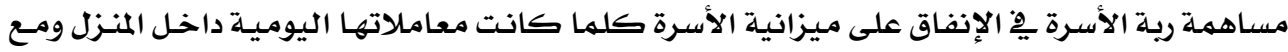

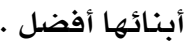
• ب الفرض الثالث :

توجـد فـروق دالـة إحصـائياً بـين أفـراد عينـة البـحثث ِِّ درجـة الاهتمـام بـالزوج تبعـاً لمتغيرات

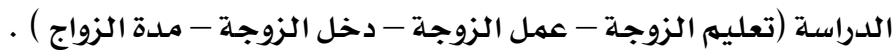
وللتحقـق مـن صسحة هــا الفـرض تم إجـراء اختبــار " ت " للوقـوف علـى دلالــة الفـروق بـين

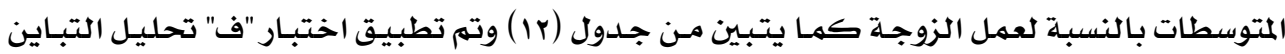

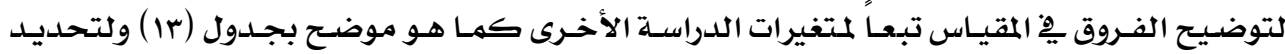

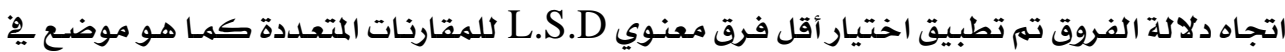

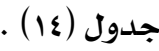

جدول (ir)

الفروق بين المتوسطات الحسابية ـِ درجة الاهتمام بالزوج تبعاً لعمل الزوجة ( تعمل - لا تعمل )

\begin{tabular}{|c|c|c|c|c|c|c|}
\hline الدلالة & قيمة "ت" & درجة & العينة & الانحـراف & الحتوسط الحسابي & عمل الزوجة \\
\hline \multirow{2}{*}{ "•, ل• تصمل } & \multirow{2}{*}{ IV,q1r } & \multirow{2}{*}{$r \cdot r$} & 159 & $r, 19 \varepsilon$ & $1 Y, .0 \varepsilon$ & تعهل \\
\hline & & & Vy & I, IRIR & $19,10 \mathrm{~V}$ & لا تعمل \\
\hline
\end{tabular}

يتضح من جدول (Y ) أن هناك فروق ذات دلالة إحصائية بين أفراد عينة الدراسـة تبعـاً لعهل

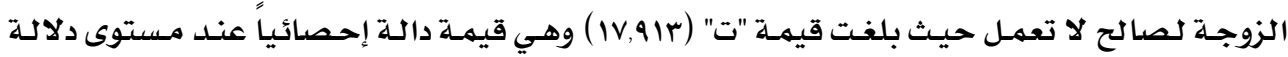

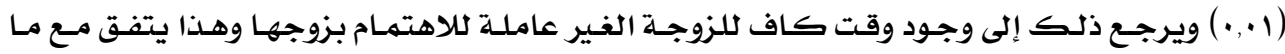

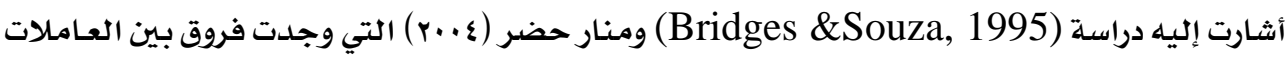

$$
\text { وغير العاملات يِّ درجة التعامل مـع الزوج لصالح غير العاملات . }
$$




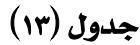

تحليل التباين لتوضيح الفروق هِ درجة الاهتمام بالزوج تبعاً لمتغيرات الدراسة (براس

\begin{tabular}{|c|c|c|c|c|c|}
\hline الدلالة & قيمـة & درجة & مـتوسط المربعات & مجمهوع المربعات & تعليـم الزورجية التباين \\
\hline \multirow{3}{*}{$\cdot, \cdot 1$} & \multirow{3}{*}{$71, \varepsilon \leqslant \wedge$} & r & $17 \cdot 9,70$. & $r \varepsilon|q, r|$ & بين المجموعات \\
\hline & & $r \cdot r$ & 19,717 & rqV7,orr & داخل المجموعات \\
\hline & & $r \cdot \varepsilon$ & & TrQ0,NYE & المجموع \\
\hline لالة & قيهـة & درجة & متتوسط & ملمجموع & إذا كانت تعمل \\
\hline \multirow{3}{*}{$\begin{array}{l}\cdot, 1 \\
\text { Ju }\end{array}$} & \multirow{3}{*}{ rr,qII } & $r$ & IV9,vrq & roq, \&vr & بين المجحموعات \\
\hline & & IrT & $\mathrm{V}, 01 \mathrm{~V}$ & $9 \varepsilon V, 1 \leqslant V$ & داخل المجهموعات \\
\hline & & IrA & & Ir.7,7r. & المجموع \\
\hline لالة & قيمـة & درجة & متوسط المربعات & مجهموع & دخل الزوجة \\
\hline \multirow{3}{*}{$\begin{array}{c}\cdot 1 \\
\text { Ju }\end{array}$} & \multirow{3}{*}{ r\&,ru } & $r$ & $r \cdot 7,0\}$ & $71 \mathrm{r}, 1 \cdot \mathrm{V}$ & بين المجهوعات \\
\hline & & IYT & $1,9 \cdot 0$ & $\| r r, \cdot \varepsilon \Lambda$ & داخل المجموعات \\
\hline & & IrA & & $1 V K \varepsilon, 100$ & المجموع \\
\hline الدلالة & قيمـة & درجة & متوسط المربعات & مجهموع & مدة الزواج \\
\hline \multirow{3}{*}{$\begin{array}{c}\cdot 1 \\
\text { Jנ }\end{array}$} & \multirow{3}{*}{ oo,rvo } & $r$ & $17 \varepsilon r \cdot V q$ & RYAT, 109 & بين المجهوعات \\
\hline & & IYT & Yq, TVY & ه994,777 & داخل المجموعات \\
\hline & & IrA & & QrVq,ArE & المجهوع \\
\hline
\end{tabular}

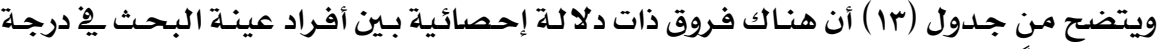

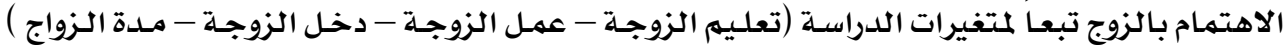

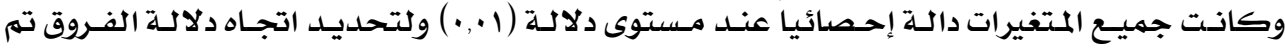

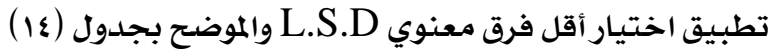


جدول (£)

الفروق بين أفراد العينة ِِِ درجة الاهتمام بالزوج تبعاً لمتغيرات الدراسة

\begin{tabular}{|c|c|c|c|}
\hline مـ = مرتفع & 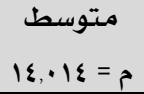 & من منفض = & تعليهم الزوجـة \\
\hline & & $-\quad-\quad-$ & منخخفض \\
\hline & $-\quad-\quad-$ & $* \&, 0 \wedge T$ & متوسط \\
\hline$-\quad-\quad-$ & $* \nLeftarrow\{, \wedge 1 \varepsilon$ & $* 4,8+1$ & مرتفـع \\
\hline \multirow[t]{3}{*}{ 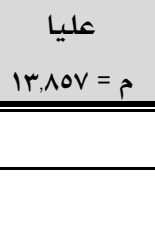 } & مت = مץوسطة & $\begin{array}{c}\text { دنيا } \\
\text { ه,AVq }\end{array}$ & إذا كانت تعمل \\
\hline & & $-\quad-\quad-$ & منخخف \\
\hline & $-\quad-\quad-$ & $* 1, \varepsilon \leqslant 7$ & متوسط \\
\hline$-\quad-\quad-$ & $*$ r,OrY & 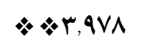 & مرتفـع \\
\hline \multirow[t]{3}{*}{ 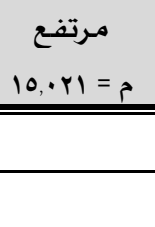 } & متوسط = مُ & من م = rخفض & دخل الزوجـة \\
\hline & & $-\quad-\quad-$ & منخخفض \\
\hline & $-\quad-\quad-$ & $\cdot, r \varepsilon V$ & متوسط \\
\hline$-\quad-\quad-\quad-$ & $* \&, \pi \mid r$ & $* \&, 109$ & مرتفـع \\
\hline \multirow[t]{3}{*}{ 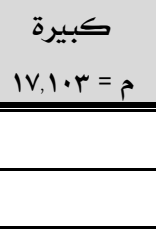 } & 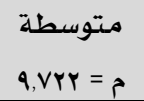 & صغيرة = & مدة الزواج \\
\hline & & $-\quad-\quad-$ & صغيرة \\
\hline & $-\quad-\quad-$ & $* \wedge, 179$ & متوسطة \\
\hline$-\quad-\quad-$ & $* \vee, r \wedge l$ & $\cdot, \mathrm{VAV}$ & كبيرة \\
\hline
\end{tabular}

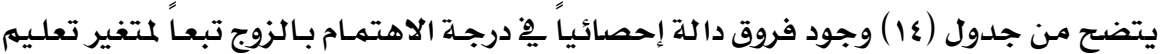

الزوجلة لكل من المستوى المرتفع والمتوسط والمنخفض حيث يتضح وجود فروق بين المستوى ( المنخفض

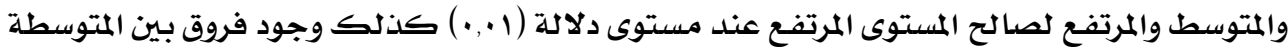

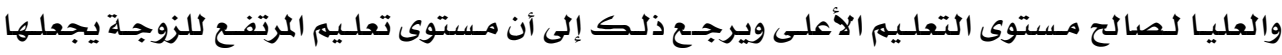

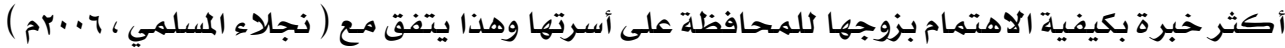
وبالنسبـة لمتغير مهنـة الزوجـة اتضح مـن جـدول ( ع ) أن هنـاك فـروق دالـة إحصـائياً بـين أفراد

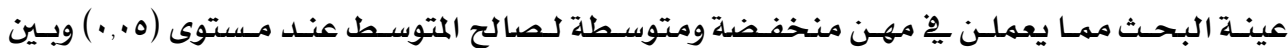

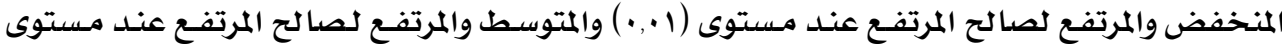




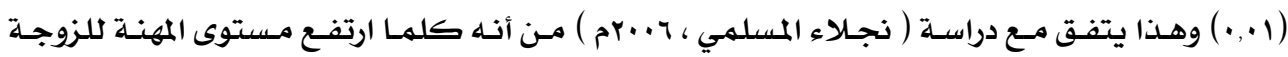

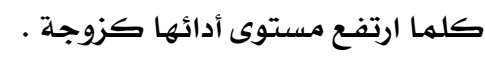

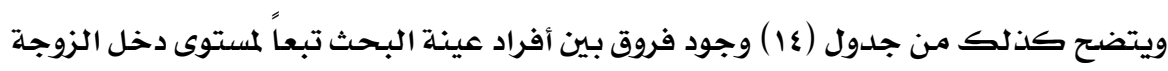

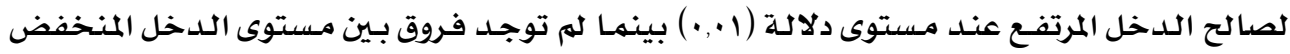

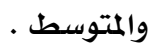

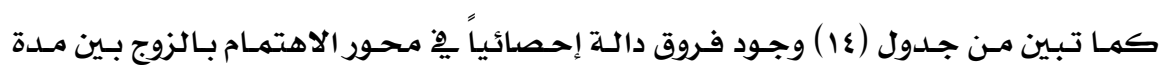

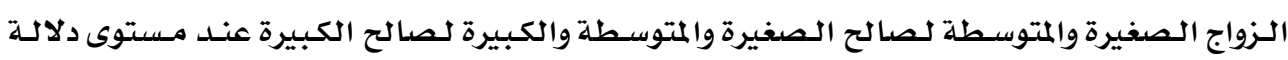

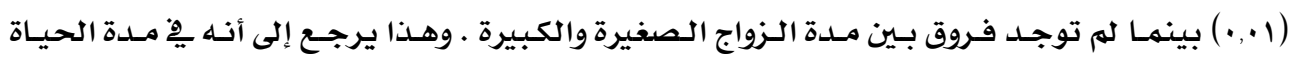

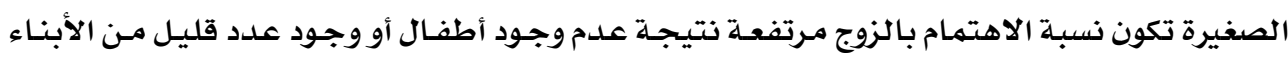

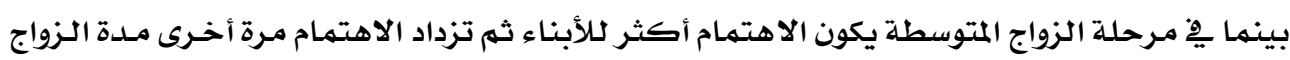
الأكبر بعد زواج الأبناء . • الفرض الرابع :

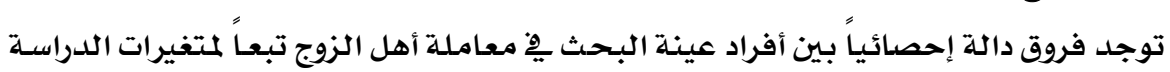

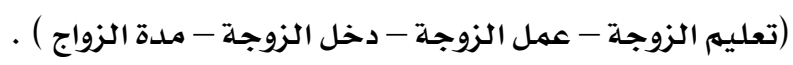

وللتحقـق مـن صسحة هـــا الفـرض تم إجـراء اختبــار " ت " للوقـوف علـى دلاكـة الفـروق بـين

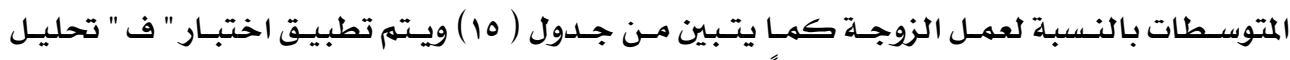

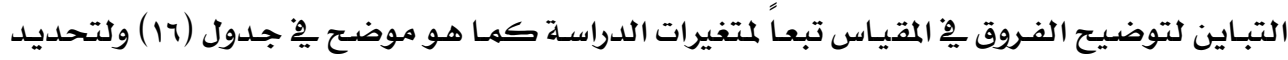

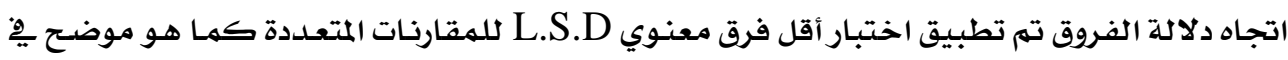

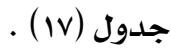

جدول (10)

الفروق بين المتوسطات الحسابية ِِِ معاملة أهل الزوج تبعاً لعمل الزوجة ( تعمل - لا تعمل )

\begin{tabular}{|c|c|c|c|c|c|c|}
\hline الدلالة & قيمـة & الحرجية & العينـة & الانحصراف & المتوسط الحسابى & عمل الزوجـة \\
\hline \multirow{2}{*}{ ع 19, • غير } & \multirow{2}{*}{$1, r \cdot \varepsilon$} & \multirow{2}{*}{$r \cdot r$} & $1 r 9$ & \&,07r & 19,9rr & تعمل \\
\hline & & & VT & V,VIr & $r_{1} \cdot r_{q}$ & لا تعمل \\
\hline
\end{tabular}

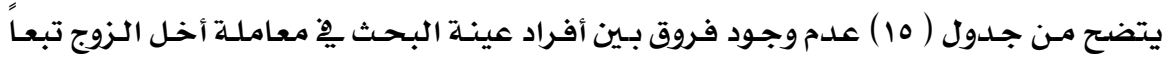

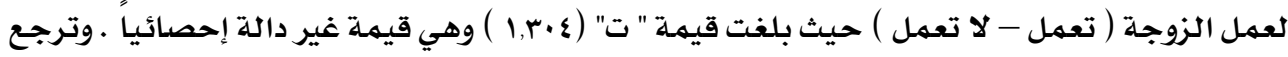

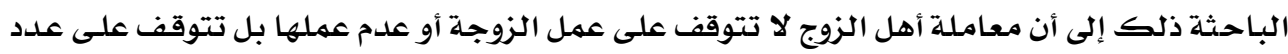

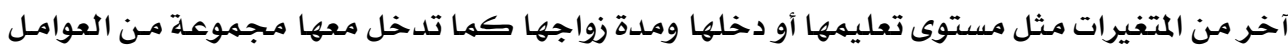


جدول (i)

تحليل التباين لتوضيح الفروق بِّ معاملة أهل الزوج تبعاً لمتغيرات الدراسة

\begin{tabular}{|c|c|c|c|c|c|}
\hline الدلالة & "قيمـة & درجة الحرية & متتوسط المربعات & مـرجموع & تعليم الزوجـة \\
\hline \multirow{3}{*}{ ו•,•• دال } & \multirow{3}{*}{ Tr, $\cdots V$} & $r$ & 199r.9VY & 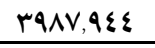 & بين المجموعات \\
\hline & & $r \cdot r$ & $r I, 7 \leqslant V$ & Trar,TIr & داخل المجموعات \\
\hline & & $r \cdot r$ & & $1 \cdot r \Lambda \cdot 077$ & المجموع \\
\hline الدلالة & "فيمـة & درجة الحريـة & متتوسط المربعات & مجرموع المربعات & إذا كانت تعمل \\
\hline \multirow{3}{*}{ ו•,•• دال } & \multirow{3}{*}{ RY,IVE } & $r$ & $\{0 .,\{9\}$ & $9 \cdots, 910$ & بين المجموعات \\
\hline & & $1 Y 7$ & $1 \varepsilon, \cdots r$ & IVT\&,Y & داخل المجمهوعات \\
\hline & & IYN & & rTTO,YYO & المجموع \\
\hline الدلالة & "فيمة & درجة الحرية & متتوسط المربعات & ملمجموع المربعات & دخل الزوجة \\
\hline \multirow{3}{*}{ ו•,•• دال } & \multirow{3}{*}{$V, \wedge 19$} & $r$ & $1 \varepsilon 7,01 \%$ & rar, $\cdot r q$ & بين المجموعات \\
\hline & & $1 Y 4$ & IA,VHV & rma.,10. & داخل المجموعات \\
\hline & & $1 Y \Lambda$ & & rYor,AVT & المجموع \\
\hline الدلاكلة & "فيمة & درجة الحريـة & متتوسط المربعات & مجرموع & مدة الزواج \\
\hline \multirow{3}{*}{ ו•,•• دال } & \multirow{3}{*}{$7 \cdot, r \vee 7$} & $r$ & $10 \& V, 109$ & $r \cdot q \varepsilon, r \mid v$ & بين المجموعات \\
\hline & & $r \cdot r$ & Yo,TYO & $01 V 7, Y \wedge V$ & داخل المجموعات \\
\hline & & $r \cdot \varepsilon$ & & $\Lambda Y V \cdot, T \cdot 0$ & المجموع \\
\hline
\end{tabular}

يتضح من جدول (1 ) أن هناك فروق ذات دلالدة إحصائية بين أفراد عينة البحث فِّ معاملـة

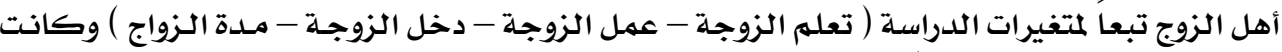

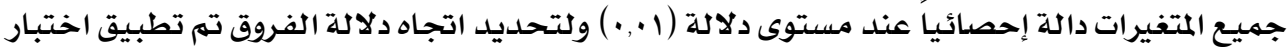

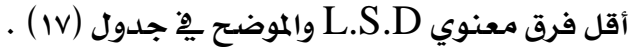


جدول (iv)

الفروق بين أفراد العينة ـِّ معاملة أهل الزوج تبعاً لمتغيرات الدراسة

\begin{tabular}{|c|c|c|c|}
\hline مرتفع = & متوسط = مبر & من = منخفض & تعليهم الزوجـة \\
\hline & & $-\quad-\quad-$ & منـخفض \\
\hline & $-\quad-\quad-$ & $* 1, \varepsilon V r$ & متتوسط \\
\hline$-\quad-\quad-\quad-$ & $\nLeftarrow \wedge \wedge, \vee \wedge \wedge$ & $* 1 \cdot, r T r$ & مرتفع \\
\hline \multirow[t]{3}{*}{$\begin{array}{c}\text { عليL } \\
\text { rr,rvo = }\end{array}$} & مت = متوسطة ...9,9 & $\begin{array}{c}\text { دنيا } \\
\text { 10, V^9 = }\end{array}$ & إذا كانت تعمل \\
\hline & & $-\quad-\quad-$ & منخخفض \\
\hline & $-\quad-\quad$ & $* \varepsilon, 11 r$ & متوسط \\
\hline$-\quad-\quad-\quad-$ & $* \forall, \& V 0$ & $* \star \neg, 0 \wedge \mathrm{V}$ & مـرتفـع \\
\hline \multirow[t]{3}{*}{ مرتفع = مرتح } & م = بتوسط & 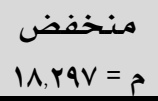 & دخل الزوجـة \\
\hline & & $-\quad-\quad-$ & منخخف \\
\hline & $-\quad-\quad-$ & •, & متوسط \\
\hline$-\quad-\quad-\quad-$ & $*$ r, V०q & $*$ r.०91 & مـرتفـع \\
\hline \multirow[t]{3}{*}{ 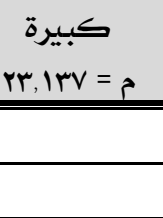 } & مت = م| •.بطة & م = سغيرة & مدة الزواج \\
\hline & & $-\quad-\quad$ & صغيرة \\
\hline & $-\quad-\quad-$ & $* 9,7.1$ & متوسطة \\
\hline$-\quad-\quad-\quad-$ & $* 1,1 r \varepsilon$ & $* * 1 \cdot, V Y \varepsilon$ & كبيرة \\
\hline
\end{tabular}

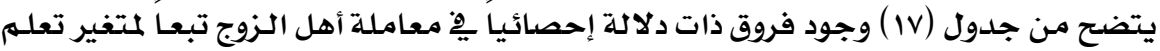

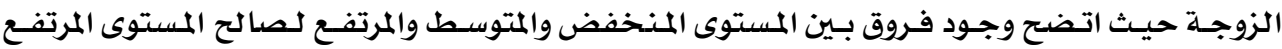

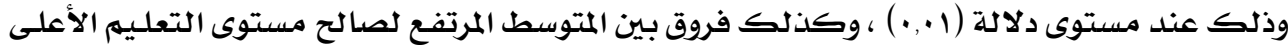

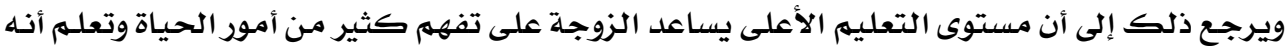
من حق الزوج على زوجته إكرام أهله وإنها عندما تحسن معاملة أهل زوجها يزيد هذا إنى من حب زوجها لها .

أما بالنسبـة لمتغير مهنة الزوجـة فقد اتضح من جدول (IV) أن هناك فروق دالـة إحصائياً بـين

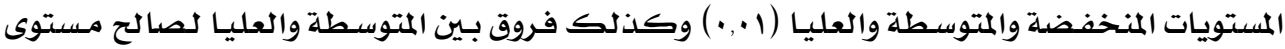

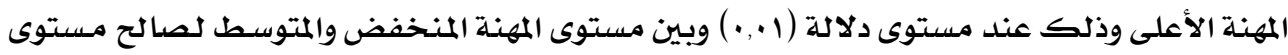
المهنة المتوسط وذلك عند مستوى دلالة (1 . . .) . 
ويتضح كذلك مـن جـدول (IV) أن هنـاك فروق دالـة إحصائياً بـين أفراد عينـة البحـث تبعـاً

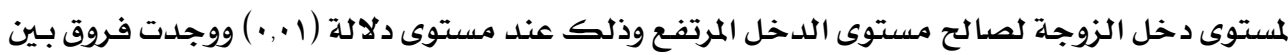

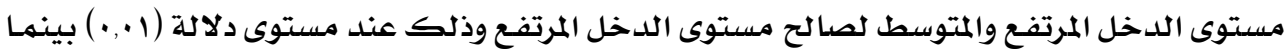

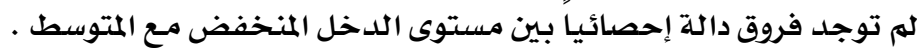

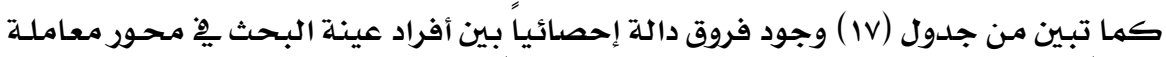

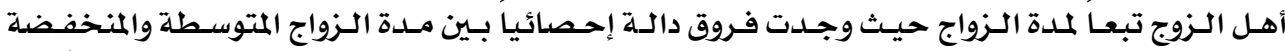

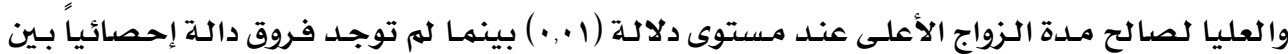

$$
\text { مدة الزواج الكبيرة والمتوسطة . }
$$

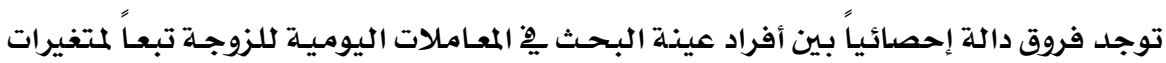

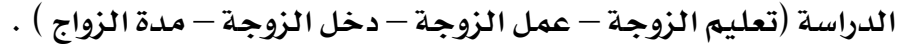

وللتحقق من هذا الفرض تم إجراء اختبـار " ت " للوقوف على دلالـة الفـروق بـين المتوسطات

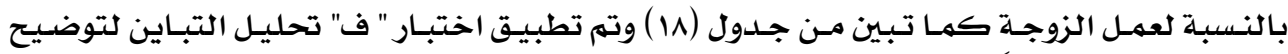

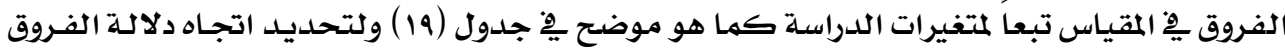

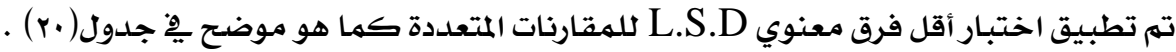

\begin{tabular}{|c|c|c|c|c|c|c|}
\hline الدلالة & "تيمة & درجة الحرية & العينـة & الانحـراف & الحتوسط الحسبي & عمل الزوجة \\
\hline \multirow{2}{*}{ غير دال } & \multirow{2}{*}{ •,V74 } & \multirow{2}{*}{$r \cdot r$} & $1 r 9$ & $V, \cdot V_{1}$ & $r \wedge, 0 \wedge 9$ & تعمل \\
\hline & & & vi & $1 \cdot, \varepsilon \mid V$ & Y৭,OY & لا تعمل \\
\hline
\end{tabular}
جدول (1)

الفروق بين المتوسطات الحسابية ٌِِ المعاملات اليومية للزوجة تبعاً للعمل ( تعمل - لا تعمل )

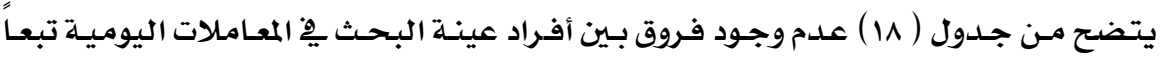

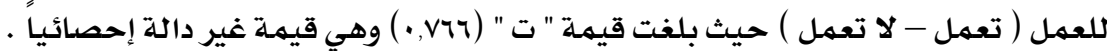


جدول (19)

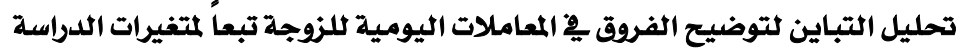

\begin{tabular}{|c|c|c|c|c|c|}
\hline الدلالة & "قيمـة & درجة الحرية & متوسط المربعات & مسجهوع & تصليـم الزورجية التباين \\
\hline \multirow{3}{*}{ 1., } & \multirow{3}{*}{$7 \cdot \Delta M I$} & r & r৭৭৭,rr. & 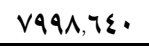 & بين المجهموعات \\
\hline & & $r \cdot r$ & $70, V \leqslant 0$ & IMYA,ETY & داخل المجهوعات \\
\hline & & $r \cdot \varepsilon$ & & rI rV9,1.r & المجموع \\
\hline الدلالة & "فيمة & درجة الدرية & متوسط المربعات & ملمجموع المربعات & إذا كانت تعمل \\
\hline \multirow{3}{*}{ 1., • دال } & \multirow{3}{*}{ rY,IYq } & r & $1 \cdot 1 \cdot, 7 \leqslant 0$ & Y17I, Y^9 & بين المجهوعات \\
\hline & & IYY & צחד,אץ & צrrv,qr & داخل المجموعات \\
\hline & & IrA & & TrQ৭, YYo & المجهوع \\
\hline الدلالية & "فيمة & درجة الحرية & متوسط المربعات & ملمجموع & دخل الزوجهة \\
\hline \multirow{3}{*}{ 1•••• دال } & \multirow{3}{*}{$10, \wedge 7 V$} & $r$ & 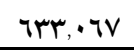 & o & بين المجموعات \\
\hline & & IYY & 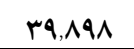 & $0 . r V, 17 \Lambda$ & داخل المجهموعات \\
\hline & & IrA & & Trqr,r.r & المجموع \\
\hline الدلالة & قيهمة & درجة الحرية & متوسط المربعات & مـجموع & مدة انزواج \\
\hline \multirow{3}{*}{ 1., } & \multirow{3}{*}{ TI,VMV } & $r$ & 8117,770 & ArVr,rrq & بين المجهوعات \\
\hline & & $r \cdot r$ & TY,VYE & |YTVY,YOI & داخل المجموعات \\
\hline & & $r \cdot \varepsilon$ & & $Y_{1} \cdot\{0,0 \wedge$. & المجموع \\
\hline
\end{tabular}

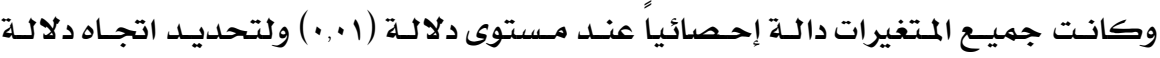

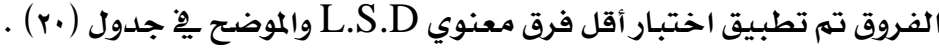




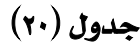

الفروق بين أفراد العينة بِ المعاملات اليومية للزوجة تبعا لمتغيرات الدراسة

\begin{tabular}{|c|c|c|c|}
\hline م = مرتفع & متوسط = ملr,r. & من = منخف & تعليهم الزوجة \\
\hline & & $-\quad-\quad-$ & منخخف \\
\hline & $-\quad-\quad-$ & $1, \vee \leqslant \wedge$ & متوسط \\
\hline$-\quad-\quad-\quad-$ & $* \mid r, 7, r$ & $* \nLeftarrow<$, rol & مرتفع \\
\hline \multirow[t]{3}{*}{ م = = عليا } & مت = م:وسطة ro,rV & $\begin{array}{c}\text { دنيا } \\
r \varepsilon, 0 V 7=r\end{array}$ & إذا كانت تعمل \\
\hline & & $-\quad-\quad-$ & منـخفض \\
\hline & $-\quad-\quad-$ & $\cdot, \vee \vee 99$ & متوسط \\
\hline$-\quad-\quad-\quad-$ & $* \nLeftarrow \mathrm{V}, \mathrm{AV} \mathrm{O}$ & $* * \wedge, 7 \vee \varepsilon$ & مـرتفـع \\
\hline \multirow[t]{3}{*}{ 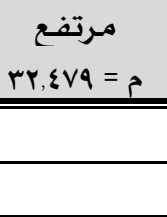 } & 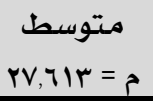 & $\begin{array}{l}\text { منخفض } \\
r \xi, V \cdot r=r\end{array}$ & دخل الزوجة \\
\hline & & $-\quad-\quad-$ & منخخف \\
\hline & $-\quad-\quad-$ & $* r, 91$. & متوسط \\
\hline$-\quad-\quad-$ & $* \& \leqslant, \wedge 70$ & $* * V, V V 7$ & مرتفـع \\
\hline \multirow[t]{3}{*}{ مبـيرة = } & مت = اوسطة & صغخيرة = & مدة الزواج \\
\hline & & $-\quad-$ & صغيرة \\
\hline & $-\quad-\quad-$ & $* * V, \varepsilon \wedge V$ & متوسطة \\
\hline$-\quad-\quad-$ & $* 1 ., 191$ & $*$ IV,TVA & كبيرة \\
\hline
\end{tabular}

يتضـح مـن جـدول ( • ) وجـود فـروق دالـة إحصائياً فِ المعـاملات اليوميـة للزوجـة تبعـاً لمتغير

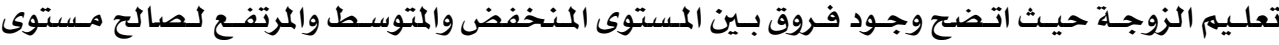

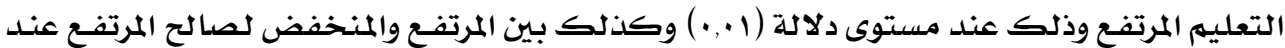

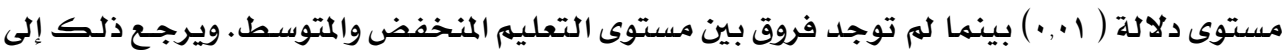

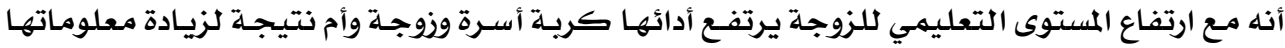

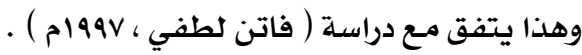

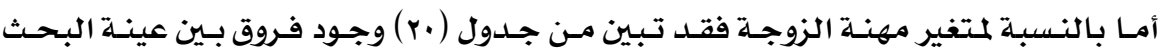

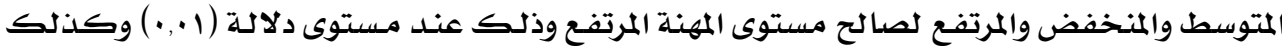

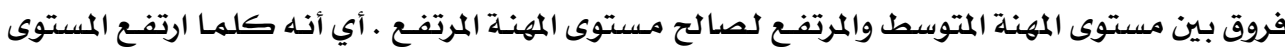




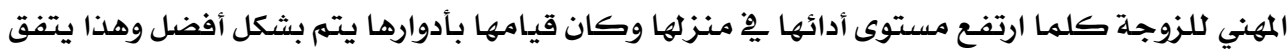

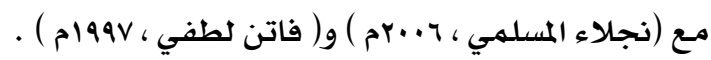

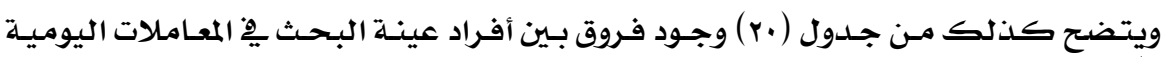

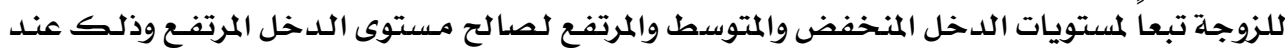

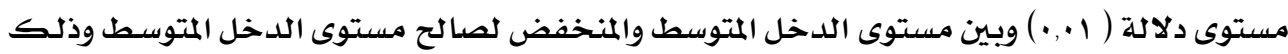

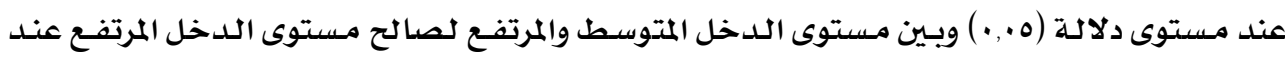

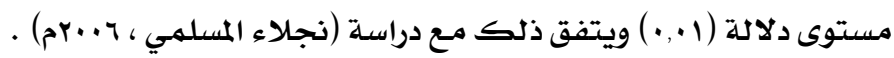

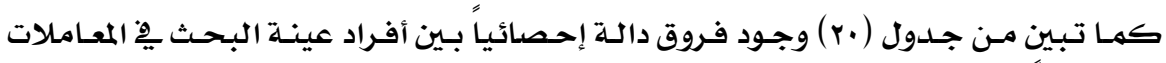

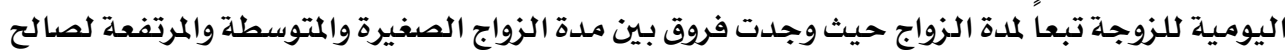

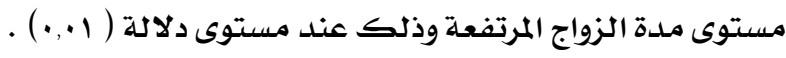

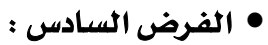

توجد فروق دالة إحصائياً بـين أفراد عينة الدراسـة ِِِ الإنفاق على بنـود الاسـتهلاك الرئيسية

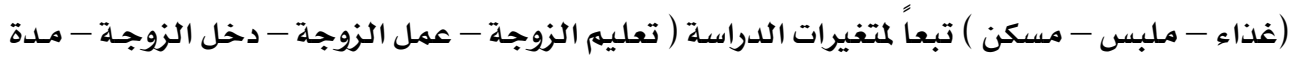
الزواج )

وللتحقـق مـن صسحة هـــا الفـرض تم إجـراء اختبــار " ت " للوقـوف علـى دلاكـة الفـروق بـين

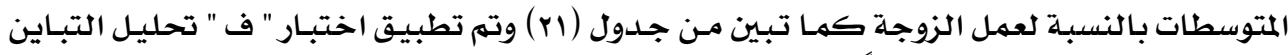

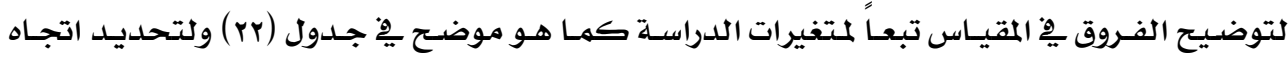

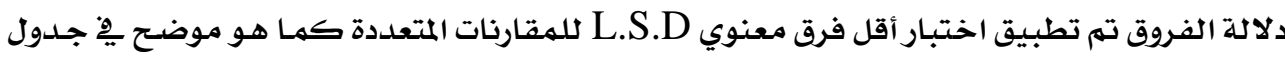

جدول (ri)

الفروق بين المتوسطات الحسابية يِّ مساهمة الزوجة يِ الإنفاق على بنود الاستهلاك الرئيسية

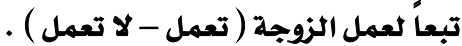

\begin{tabular}{|c|c|c|c|c|c|c|}
\hline الدلالة & "تيمة & الحرجية & العينـة & الانحراف & المتوسط الحسبي & عمل الزوجـة \\
\hline \multirow{2}{*}{ I.,· تصمل } & \multirow{2}{*}{$10, \mathrm{VVr}$} & \multirow{2}{*}{$r \cdot r$} & irq & $\varepsilon, Y \wedge \varepsilon$ & rl, Irq & تعمل \\
\hline & & & VT & r,VAr & $\mid r, \varepsilon V r$ & لا تعمل \\
\hline
\end{tabular}

يتضح من جدول (Yl ) أن هناك فروق ذات دلالة إحصائية بين أفراد عينـة الدراسـة ِيِ الإنفـاق

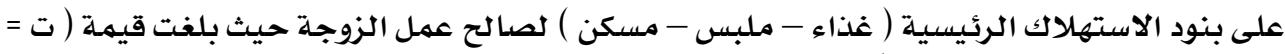

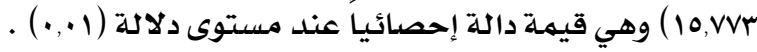


جدول (rr)

تحليل التباين لتوضيح الفروق يف المساهمة للزوجة في الإنفاق على بنود الاستهلاك الرئيسية

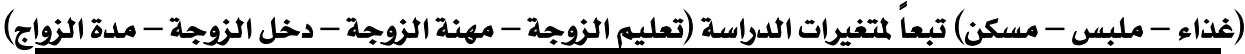

\begin{tabular}{|c|c|c|c|c|c|}
\hline الدلالة & "فيمة & الحرجية & متوسط المربعات & مـرجموع & تعليهم الزوجـة \\
\hline \multirow{3}{*}{ 1., • دال } & \multirow{3}{*}{ Or,, .0} & $r$ & $19\{\Lambda, \cdot 97$ & 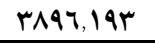 & بين المجموعات \\
\hline & & $r \cdot r$ & $r V, I V \varepsilon$ & $v 0.9,1.0$ & داخل المجموعات \\
\hline & & $r \cdot \varepsilon$ & & $11 \varepsilon \cdot 0$, rq1 & المجموع \\
\hline الدلالة & قيمة & درجة & متوسط المربعات & ملمجموع المربعات & إذا كـانت تعمل \\
\hline \multirow{3}{*}{ 1., • دال } & \multirow{3}{*}{$r q, r \cdot r$} & $r$ & $0 \leqslant q, V Y q$ & $1.99,80 \mathrm{~V}$ & بين المجموعات \\
\hline & & IrT & $1 \varepsilon, \cdot r \mu$ & IV77, 179 & داخل المجمهوعات \\
\hline & & $1 Y \Lambda$ & & YAT7,rYT & المجموع \\
\hline الدلالة & قيمـة & الحرجية & متوسط المربعات & مـجموع المربعات & دخل الزوجة \\
\hline \multirow{3}{*}{ ו.,•• دال } & \multirow{3}{*}{$\varepsilon Y, 99 Y$} & $r$ & rr., & $11 Y \cdot, \cdot 70$ & بين المجموعات \\
\hline & & IrT & דוץ.r., & |7\&|,rr. & داخل المجمهوعات \\
\hline & & & & rVTI, rqo & المجمموع \\
\hline الدلالة & "فيمـة & درجة & متوسط المربعات & مـجمورع & مدة الزواج \\
\hline \multirow{3}{*}{ دال } & \multirow{3}{*}{$0\{, \cdot 1 q$} & r & $1170,0.9$ & & بين المجموعات \\
\hline & & $r \cdot r$ & $r 1,0 \leqslant \Lambda$ & EROY,TT9 & داخل المجموعات \\
\hline & & $r \cdot \varepsilon$ & & 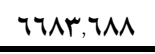 & المجموع \\
\hline
\end{tabular}

يتضح من جدول (rr) أن هناك فروق ذات دلالة إحصائية بين أفراد عينة البحث فِ المساهمة

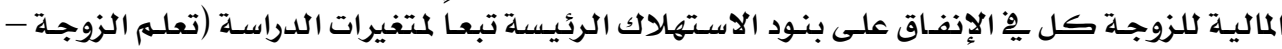

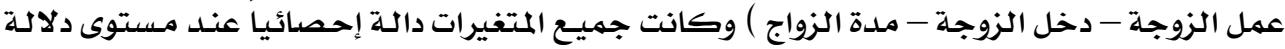

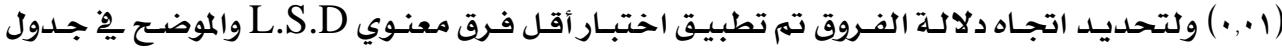


جدول (rr)

الفروق بين أفراد عينة البحث يِ مساهمة الزوجة المالية للإنفاق على بنود الاستهلاك الرئيسية

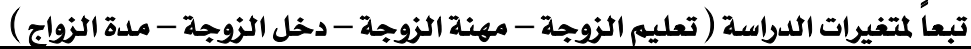

\begin{tabular}{|c|c|c|c|}
\hline مـ = مرتفـع & مت متوسط & من = م-شفضض & المتغير تعليه الزوجلة \\
\hline & & $-\quad-\quad-$ & منخفض \\
\hline & $-\quad-\quad-$ & $\cdot, Y q$ & متوسط \\
\hline$-\quad-\quad-$ & $* 9,17 \varepsilon$ & $* 4, \vee 9 \varepsilon$ & مرتفع \\
\hline $\begin{array}{c}\text { عليا } \\
r \&, 7 \leqslant r=1\end{array}$ & $\begin{array}{l}\text { متوسطة = } 19,19 \\
\end{array}$ & 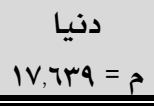 & إذا كانت تعمل \\
\hline & & $-\quad-\quad-$ & منخخف \\
\hline & $-\quad-\quad$ & $* 1,\{\wedge 9$ & متتوسط \\
\hline--- & $* 0,011$ & $* * V, \cdots 7$ & مرتفع \\
\hline 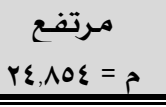 & 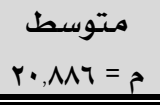 & من = منفضض & دخل الزوجـة \\
\hline & & $-\quad-\quad-$ & منخخض \\
\hline & $-\quad-\quad$ & $* \& \varepsilon$, Yา & متوسط \\
\hline$-\quad-\quad-\quad$ & $* 4$ r.,97V & $* * \wedge, r \mu r$ & مرتفـع \\
\hline 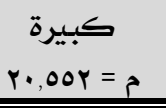 & مت = متوسطة & م = صغيرة & مدة الزواج \\
\hline & & $-\quad-\quad$ & صغيرة \\
\hline & $-\quad-\quad$ & $* \vee v, 0 . \varepsilon$ & متوسطة \\
\hline$-\quad-\quad-$ & $*$ (1,7ro & $* 4,1 \mu \wedge$ & كبيرة \\
\hline
\end{tabular}

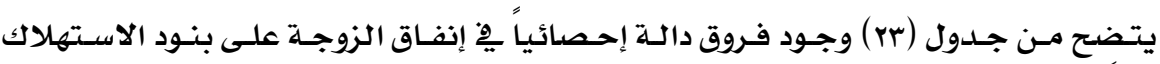

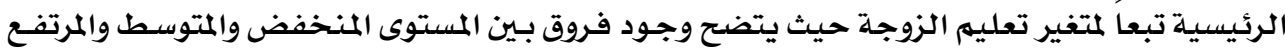

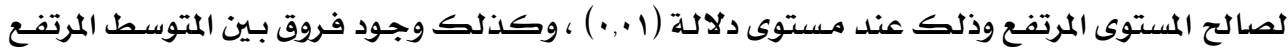

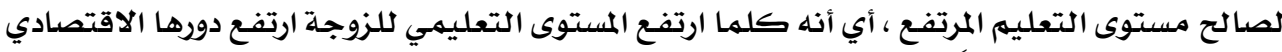

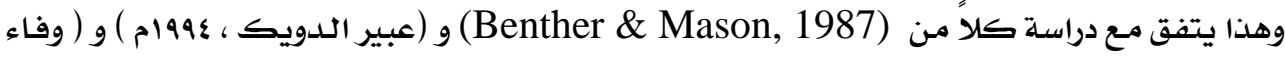

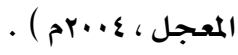

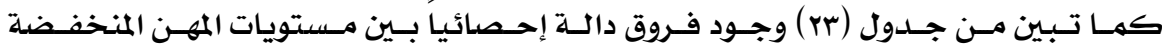

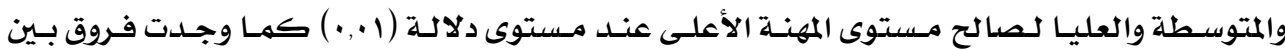

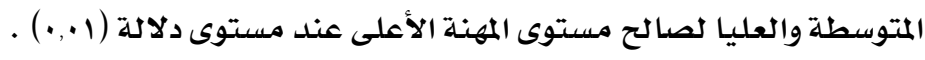




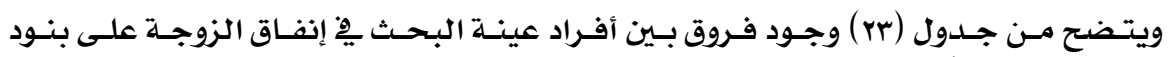

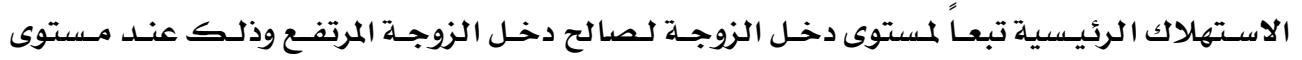
دلادة(1) (•)

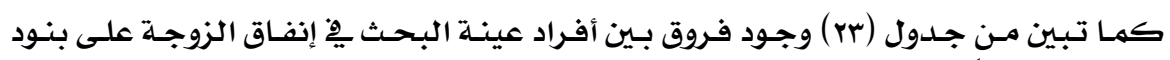

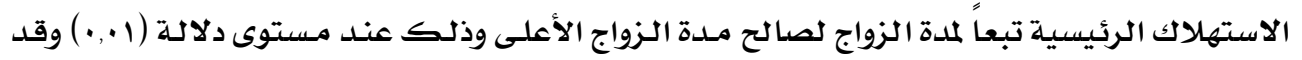

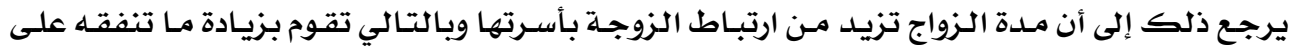
أسرتها

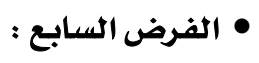

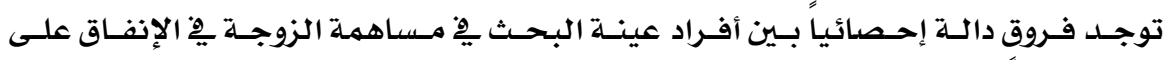

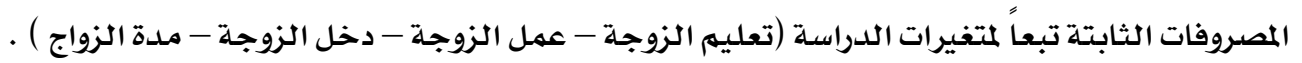

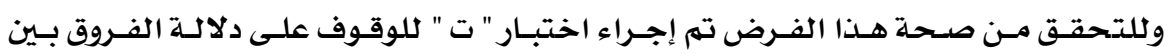

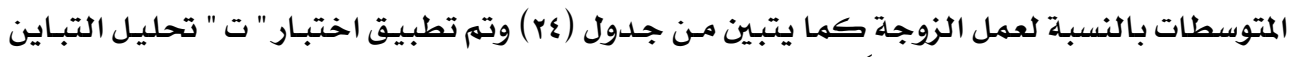

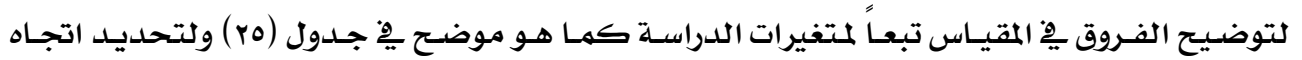

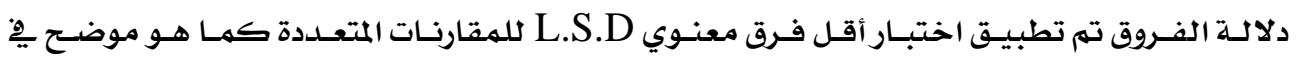

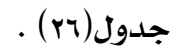

جدول (r)

الفروق بين المتوسطات الحسابية ِِِ مساهمة الزوجة يِّ الإنفاق على المصروفات الثابتة

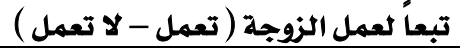

\begin{tabular}{|c|c|c|c|c|c|c|}
\hline الدلالة & "تيمـة & درجة الحرية & العينـة & الانحـراف المعياري & المتوسط الحسابي & عمل الزوجـة \\
\hline \multirow{2}{*}{ "•,•• لصمالح } & \multirow{2}{*}{$I V, \cdots 0$} & \multirow{2}{*}{$r \cdot r$} & $1 Y 9$ & $r, Y \cdot O$ & Ir,QYY & تعمل \\
\hline & & & vi & $1, \wedge \varepsilon q$ & A,|r| & لا تعمل \\
\hline
\end{tabular}

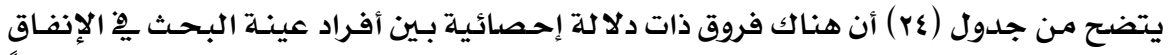

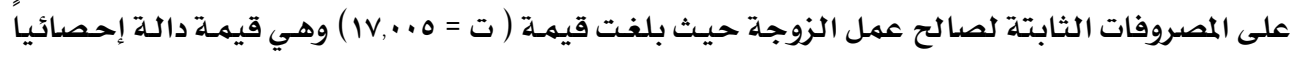

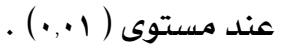


جدول (ro)

تحليل التباين لتوضيح الفروق يِّ المساهمة المالية للزوجة يُ الإنفاق على المصروفات الثابتة

\begin{tabular}{|c|c|c|c|c|c|}
\hline الدلالة & "فيمة & الحرجية & متوسط المربعات & مجموع المربعات & تعليم الزوجـة \\
\hline \multirow{3}{*}{ ו•,•• دال } & \multirow{3}{*}{1, r^o } & $r$ & $117,71$. & ITr,Yr. & بين المجموعات \\
\hline & & $r \cdot r$ & $19, V r r$ & raAD,AY & داخل المجموعات \\
\hline & & $r \cdot \varepsilon$ & & $0719, \varepsilon \varepsilon$ & المجموع \\
\hline الدلالة & "فيمسة & درجية & متوسط المريعات & مجموع المربعات & إذا كانت تعهل \\
\hline \multirow{3}{*}{ ו•,•• دال } & \multirow{3}{*}{ or,074 } & $r$ & r19,7q. & $\varepsilon r q, r \wedge$. & بين المجموعات \\
\hline & & $1 Y 4$ & $\varepsilon, \vee 19$ & OrT, O19 & داخل المجموعات \\
\hline & & IrA & & 970,979 & المجموع \\
\hline الدلالة & "فيمسة & درجية & متوسط المريعات & مجموع المربعات & دخل الزوجة \\
\hline \multirow{3}{*}{ 1., دالة } & \multirow{3}{*}{ r., r.tי } & $r$ & $1 \varepsilon r, 190$ & 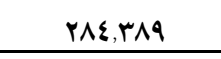 & بين المجموعات \\
\hline & & $1 Y 4$ & $\varepsilon, 7 \varepsilon Y$ & $0 \wedge \varepsilon, \wedge$ O & داخل المجموعات \\
\hline & & IrA & & 179, rYo & المجموع \\
\hline الدلالة & "فيمة & درجية & متوسط المريعات & مجموع المربعات & مدة الزواج \\
\hline \multirow{3}{*}{ إ.,• دال } & \multirow{3}{*}{$\varepsilon \vee, Y \wedge$. } & $r$ & 77,997 & Irr,৭9r & بين المجموعات \\
\hline & & $r \cdot r$ & $\mid \varepsilon, 1 \cdot V$ & $Y \wedge \Sigma 9,790$ & داخل المجموعات \\
\hline & & $r \cdot \varepsilon$ & & $\sum \mid \wedge r, T \wedge \Lambda$ & المجموع \\
\hline
\end{tabular}

يتضح من جدول (ro ) أن هناك فروق ذات دلالة إحصائية بين أفراد عينة البحث بِ فِ المساهمة

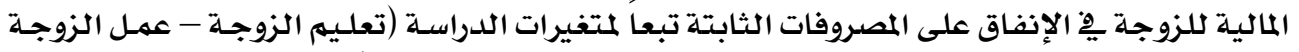

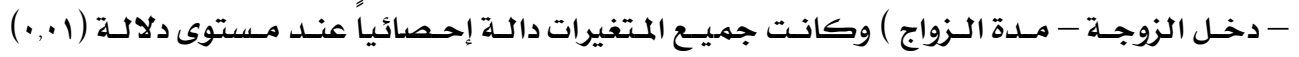

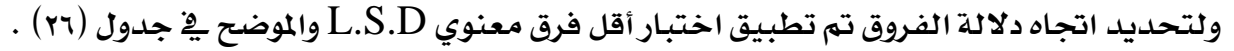




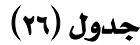

الفروق بين أفراد عينة البحث فِ مساهمة الزوجة المالية للإنفاق على المصروفات الثابتة

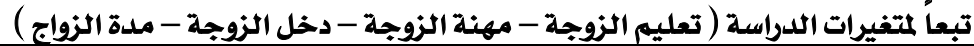

\begin{tabular}{|c|c|c|c|}
\hline مـرتفع = هץr & مت م=وسط = ., & 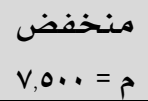 & المتغير تعليه الزوجة \\
\hline & & $-\quad-\quad-$ & منـخفض \\
\hline & $-\quad-\quad-$ & $\nLeftarrow<, 0 \ldots$ & متتوسط \\
\hline$-\quad-\quad-\quad-$ & $* \varepsilon, r Y q$ & $* V, \wedge r q$ & مـرتفع \\
\hline عليا & متوسطة & دنيا & إذا كانت تعمل \\
\hline $\mid r, \Lambda O V=\hat{~}$ & 11,rYo = & $\mid r, \ldots=\hat{r}$ & \\
\hline & & $-\quad-\quad-$ & منخخفض \\
\hline & $-\quad-\quad-$ & $\cdot, \varepsilon \vee 0$ & متوسط \\
\hline$-\quad-\quad-$ & $* \star 4, \pi \mid \varepsilon$ & $* \&, \cdot \wedge q$ & مـرتفـع \\
\hline مـرتفـع & متوسط & منـخفض & دخل الزوجهة \\
\hline $10, V V \mid=p$ & $|r, r| \Lambda=\beta$ & $\mid r, r \varepsilon r=p$ & \\
\hline & & $-\quad-\quad-$ & منـخفض \\
\hline & $-\quad-\quad-$ & $1, \cdot v \varepsilon$ & مـتوسط \\
\hline$-\quad-\quad-\quad-$ & $* *$ r,zor & $* *$ H,OYA & مـرتفـع \\
\hline كبيرة & متوسطة & صغيرة & مدة الزواج \\
\hline $\mid V, r \cdot r=p$ & $Q, V Y Y=\beta$ & $|V, \wedge 9|=\hat{~}$ & \\
\hline & & $-\quad-\quad-$ & صغيرة \\
\hline & $-\quad-\quad-$ & $* \cdot 9 \wedge 7$ & مـتوسطة \\
\hline$-\quad-\quad-$ & $* 0,9 V$ & $* * 7, \cdot \wedge r$ & كبـيرة \\
\hline
\end{tabular}

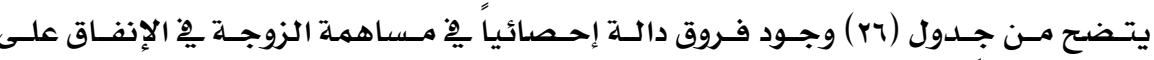

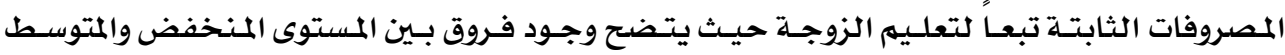

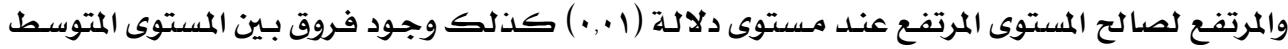

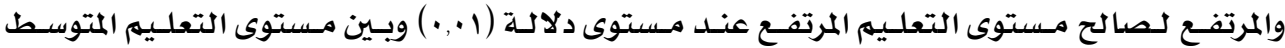
والمنخفض لصالح مستوى التعليم المتوسط وذلك عند المند مستوى دلالة (1 .,.).

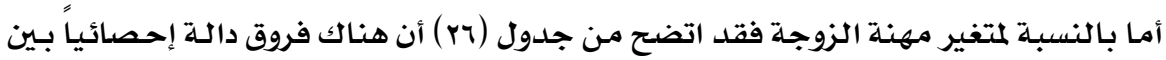

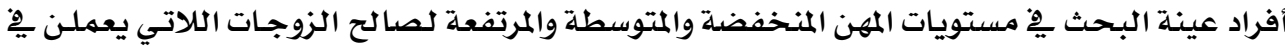
مهن مرتفعة وذلك عند مستوى دلالة (1 .,.) . 


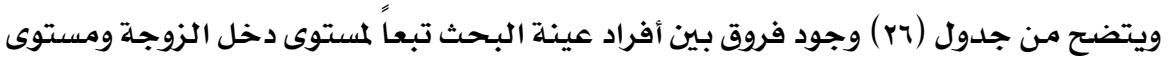

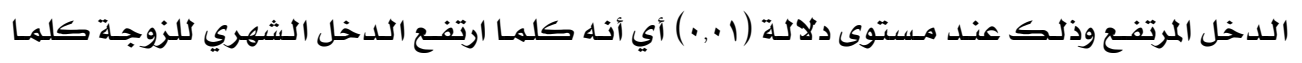

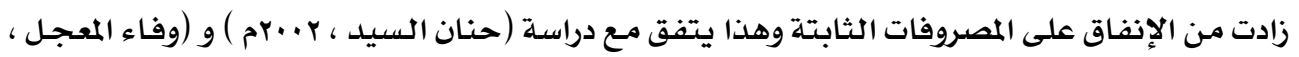

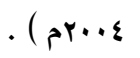

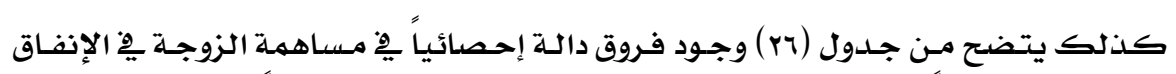

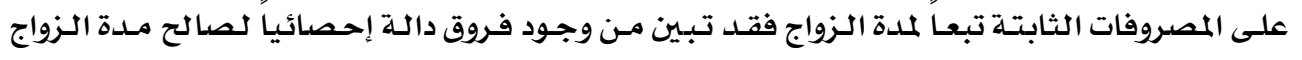
الأعلى وذلك عند مستوى دلالة (1. . ) ) .

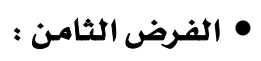

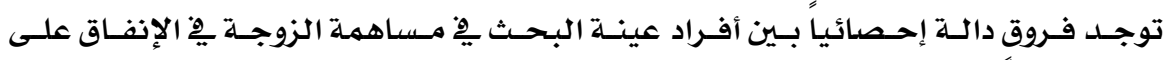

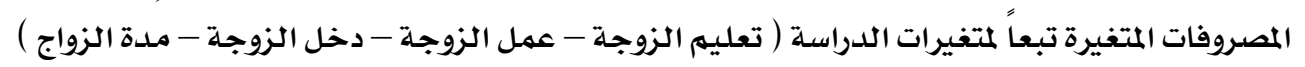

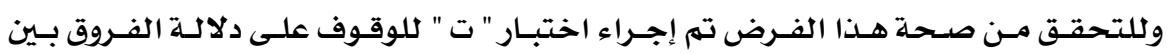

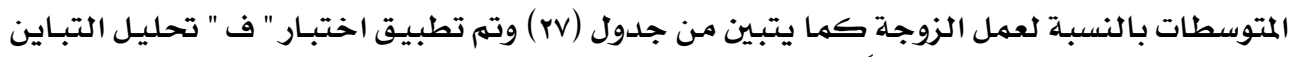

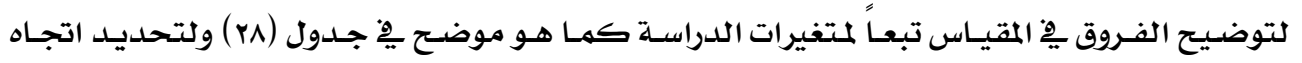

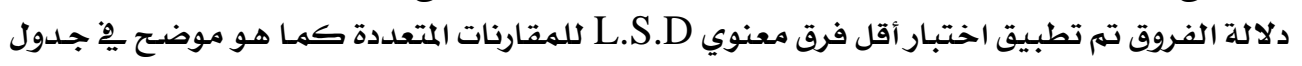

\section{جدول (rv)}

الفروق بين المتوسطات الحسابية يِّ مساهمة الزوجة بِ الإنفاق على المصروفات المتغيرة

\begin{tabular}{|c|c|c|c|c|c|c|}
\hline الدلالة & "تيمة & الحرية & العينة & الانحراف المعياري & الحتوسط الحسبى & عمل الزوجـة \\
\hline \multirow{2}{*}{ ๑ •, • لصالح } & \multirow{2}{*}{ Y,YQA } & \multirow{2}{*}{$r \cdot r$} & $1 r q$ & $\varepsilon, 17 \mathrm{~V}$ & $1 \varepsilon, \varepsilon \cdot r$ & تعمل \\
\hline & & & 17 & $\{, \varepsilon 17$ & $1 Y, 9 \wedge 7$ & لا تعمل \\
\hline
\end{tabular}

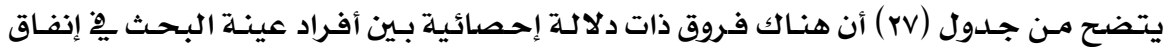

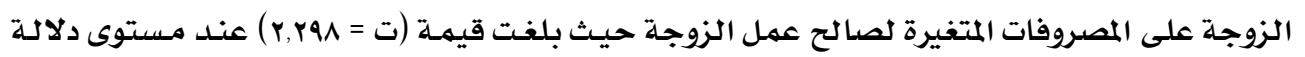
.$(\cdot, \cdot 0)$ 


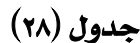

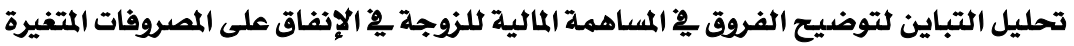

تبعاً لمتغيرات الدراسة ( تعليم الزوجة - مهنة الزوجة - دخل الزوجة - مدة الزواج )

\begin{tabular}{|c|c|c|c|c|c|}
\hline الدلالة & "فيمة & درجة الحرية & متوسط المربعات & مـجموع المربعات & تعليـم الزوجـة التبـاين \\
\hline \multirow{3}{*}{ ו•,•• دال } & \multirow{3}{*}{01,111} & $r$ & $\vee \vee Q, 0\}$. & 1009.199 & بين المجموعات \\
\hline & & $r \cdot r$ & $10, r y q$ & $r \cdot V 7, Y 19$ & داخل المجموعات \\
\hline & & $r \cdot \varepsilon$ & & 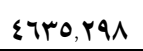 & المجموع \\
\hline الدلالة & "فيهـة & درجة الحرية & متوسط المربعات & مـرجموع المربعات & إذا كانت تعمل \\
\hline \multirow{3}{*}{ 1.,••دال } & \multirow{3}{*}{ 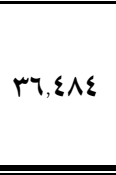 } & $r$ & $\varepsilon \cdot V, T r Y$ & N10,YרE & بين المجموعات \\
\hline & & 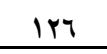 & $11,1 \mathrm{Vr}$ & $1 \varepsilon \cdot v, V v_{0}$ & داخل المجموعات \\
\hline & & IrA & & rrrr,.rq & المجموع \\
\hline الدلادلة & "فيمة & درجة الحرية & متوسط المربعات & مجرموع & دخل الزوجلة \\
\hline \multirow{3}{*}{ ו•.•• دال } & \multirow{3}{*}{$0, \cdots r$} & r & $\wedge r, \wedge \varepsilon \wedge$ & $17 V, 790$ & بين المجمهوعات \\
\hline & & $1 Y 7$ & $17, V 7 \varepsilon$ & rIIr,rr. & داخل المجموعات \\
\hline & & IYA & & YYA.,.1T & المجموع \\
\hline الدلالة & "قيمة & درجة الحريـة & متوسط المربعات & مجرموع المربعات & مدة الزواج \\
\hline \multirow{3}{*}{ ו•,•• دال } & \multirow{3}{*}{$r 9,1 \cdot 1$} & $r$ & EYV,YYA & $10\},\{07$ & بين المجموعات \\
\hline & & $r \cdot r$ & $1 \varepsilon, 7 V V$ & Y৭T\&,VA & داخل المجموعات \\
\hline & & $r \cdot \varepsilon$ & & rN19, rrq & المجموع \\
\hline
\end{tabular}

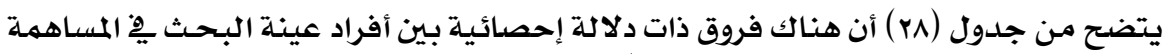

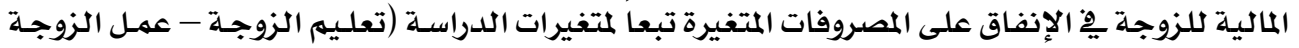

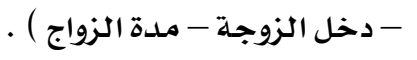

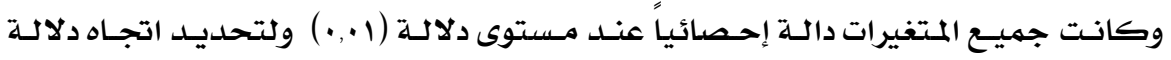
الفروق تم تطبيق اختبار أقل فرق معنوي L.S.D والموضح مِّْ جدول (ra) . 


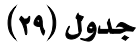

الفروق بين أفراد عينة البحث يِّ مساهمة الزوجة المالية للإنفاق على المصروفات المتغيرة

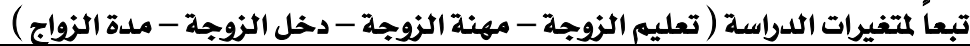

\begin{tabular}{|c|c|c|c|}
\hline 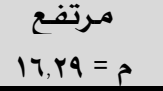 & م = متوسط & من منغفض & المتغير تعليم الزوجة \\
\hline & & $-\quad-\quad-$ & منخخض \\
\hline & $-\quad-\quad-$ & $* 7,100$ & متوسط \\
\hline$-\quad-\quad-$ & $* 1,1 \ldots$ & $* \forall, Y 00$ & مرتفـع \\
\hline \multirow[t]{3}{*}{$\begin{array}{c}\text { عليا } \\
17, \varepsilon r q=r\end{array}$} & متوسطة & $\begin{array}{c}\text { دنيا } \\
1 \cdot r \varepsilon r=r\end{array}$ & إذا كانت تعمل \\
\hline & & $-\quad-\quad-$ & منخخف \\
\hline & $-\quad-\quad-$ & $* \nLeftarrow \varepsilon, \mathrm{V} \otimes \wedge$ & متتوسط \\
\hline$-\quad-\quad-\quad-$ & $* 1, \varepsilon r q$ & $* * 7,117$ & مـرتفـع \\
\hline \multirow[t]{3}{*}{ 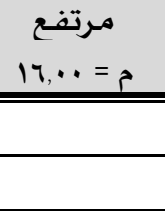 } & $\begin{array}{l}\text { متوسط = } \\
\mid r, V Y V=0\end{array}$ & من = مسا, م| & دخل الزوجـة \\
\hline & & $-\quad-\quad-$ & منخفض \\
\hline & $-\quad-\quad-$ & $.09 r$ & هتوسط \\
\hline$-\quad-\quad-\quad-$ & $* \nLeftarrow$ r, rVY & 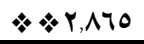 & مـرتفع \\
\hline \multirow[t]{3}{*}{ 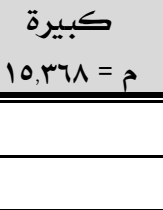 } & مت = مبوسطة & م = صغيرة & مدة الزواج \\
\hline & & $-\quad-\quad-$ & صغيرة \\
\hline & $-\quad-\quad-$ & $* \nLeftarrow \varepsilon, \varepsilon \wedge \varepsilon$ & متوسطة \\
\hline$-\quad-\quad-\quad-$ & $\cdot, \wedge \varepsilon$. & $* * 0$, rrg & كبيرة \\
\hline
\end{tabular}

يتضح من دول (rq) وجود فروق دالة إحصائياً يِّ مساهمة الزوجة بِ الإنفاق على المصروفات

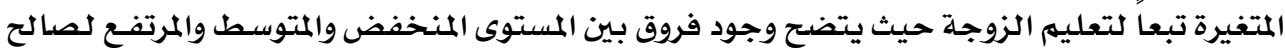

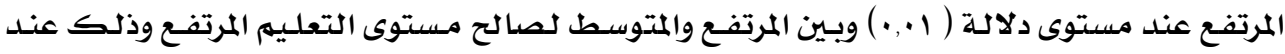

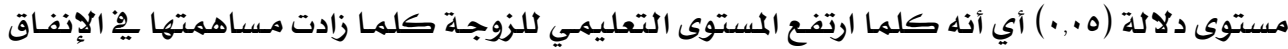

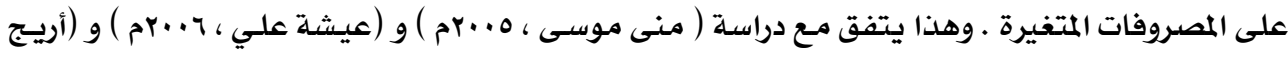

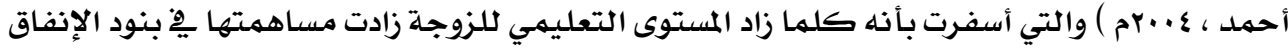


$\underline{\underline{ }}$

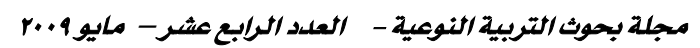

أما بالنسبة لمتغير مهنة الزوجـة فقد اتضح من جدول (rو) أن هناك فروق دالـة إحصائياً بـين

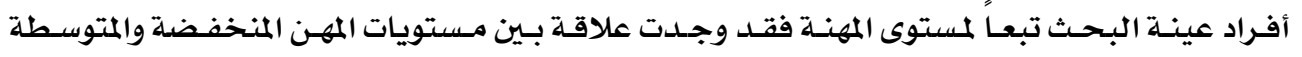

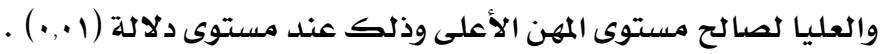

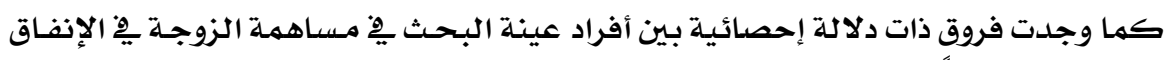

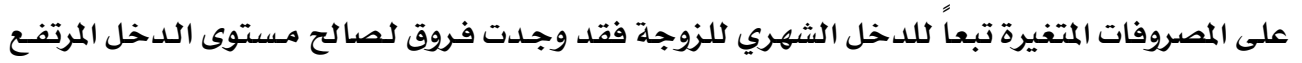

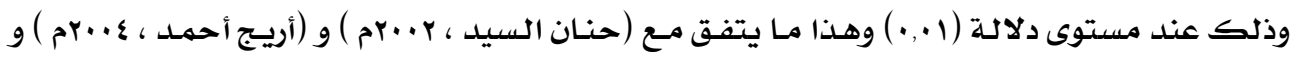

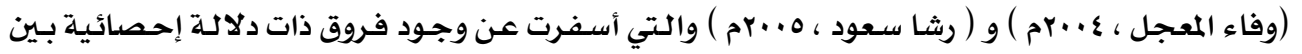

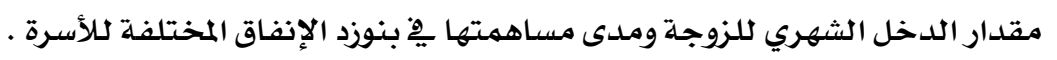

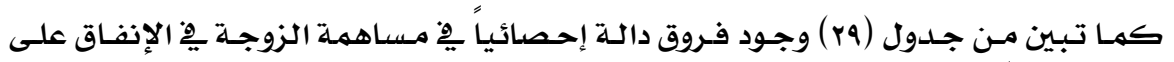

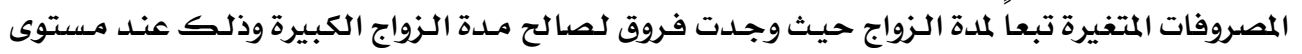

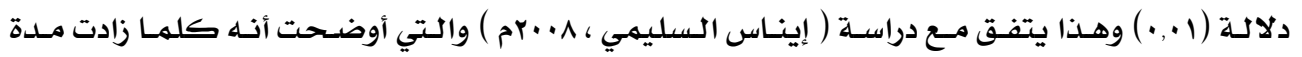

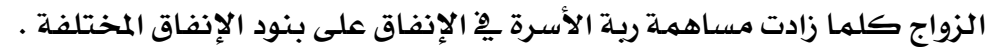

$$
\text { • الفرض التاسـع : }
$$

تتحلدد نسبة مشاركة المتغيرات المستقلة متغيرات الدراسـة ، مـع المتغيرات التابعـة (المسـاهمة

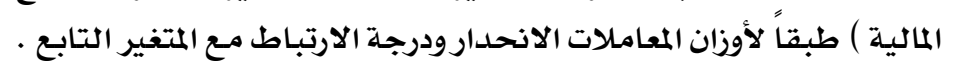

وللتحقق من صدحة هذا الفرض تم إجراء تحليل الانحدار المتعدد بطريقة الخطوة المتدرجـة

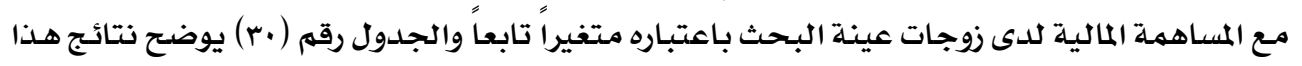

$$
\text { التحليل مع اهمباه }
$$

\begin{tabular}{|c|c|c|c|c|c|c|c|c|}
\hline الدلادة & قيمة & معامل الانحدار & الدلالة & قيمة & نسبة & معامل الارتباط & المستغير & \\
\hline$\cdot, \cdot 1$ & YY,AYG & 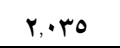 & $\cdot ., 1$ & or 1,110 & $\cdot$, Vr. & $\cdot, \wedge \varepsilon \wedge$ & دخل الزوجة & \multirow{4}{*}{ 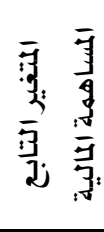 } \\
\hline$\cdot, \cdot 1$ & 17,71 & Y, $\cdot r_{0}$ & $\cdot, \cdot 1$ & rVA,YrE & $\cdot, 0 \vee \wedge$ & •, V7. & تعليم الزوجة & \\
\hline., 1 & IY,IAV & 1,179 & $\cdot .1$ & $|\Sigma \wedge, 0| V$ & •, \&YY &., 70. & مهنة الزوج & \\
\hline., 1 & $1 \cdot, 877$ & $1, \vee \leqslant \Lambda$ &., .1 & 1.9,0rr & , ro. & .094 & تعليم الزوج & \\
\hline
\end{tabular}

جدول (r.)

تحليل الانحدار المتعدد بطريقة الخطوة المتدرجة للأمام للمتغيرات المستقلة ( متغيرات الدراسة )

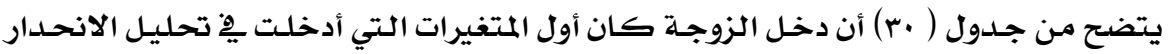

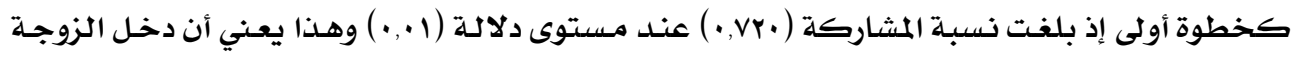

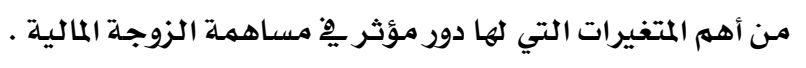




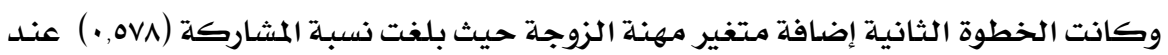

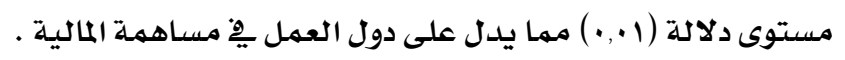

ثم كانت الخطوة الثالثة وهو دخـول مـتغير تعليهم الزوجـة لتصل نسبة المشاركة (سبع, •)

$$
\text { عند مستوى دلالة (1... •) . }
$$

ثم جاءت الخطوة الرابعة وهي مدة الزواج بنسبة مشاركة ( •مr, • عند مستوى دلالة (1... •)

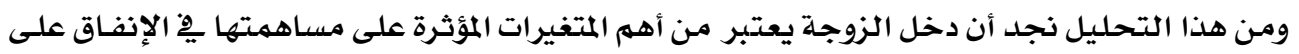

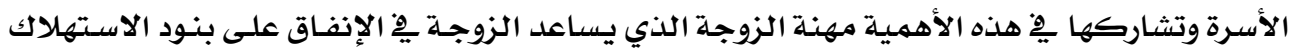

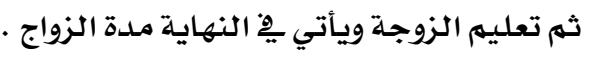
توصيات البمث : تهربه

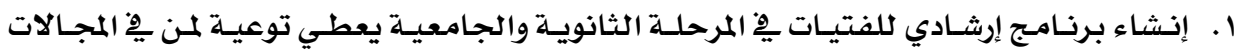
التالية :

$$
\begin{aligned}
& \text { أ - إدارة الدخل المالي . } \\
& \text { ب - فن التعامل مـع الزوج . } \\
& \text { ج - حقوق وواجبات الزوجين . }
\end{aligned}
$$

r. ت تنظيم دورات تدريبية لأسر العاملات لمعرفة كيفية التعامل المالي مـ الزوج وتأثير ذلك على

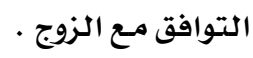

r. إجـراء حمـلات توعيـة بواسـطة وسـائل الإعـلام المختلفــة تسـتهدف التوعيـة بحقـوق وواجبـات

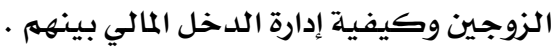


ا. إحسان النقلي ودرية أمـين (991ام ) : التخطيط والإدارة يِ الاقتصاد المنزلي - مكتبة الأنجلو المصرية -

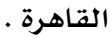

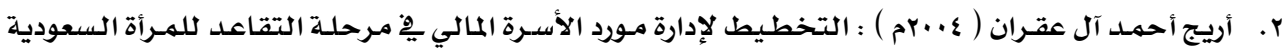

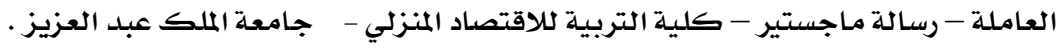

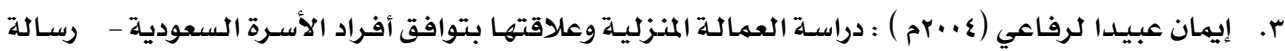

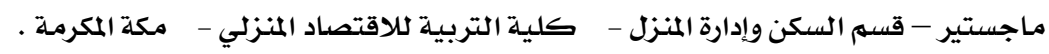

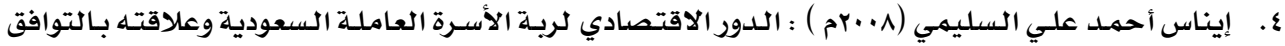
الزواجي - رسالة ماجستير - كلية التربية للاقتصاد المنزلي - جامعة أم القرى .

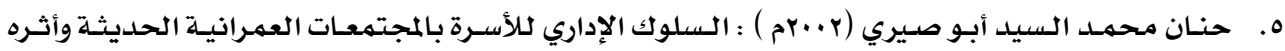

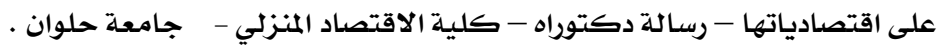

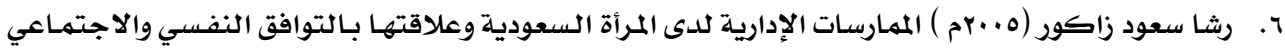

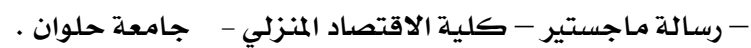

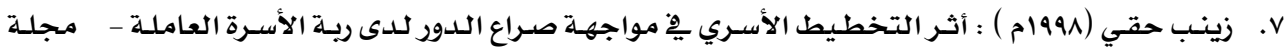

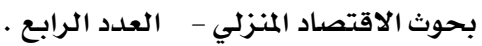

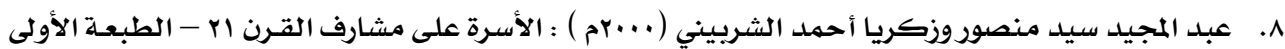
- - مار الفكر العربي - القاهرة .

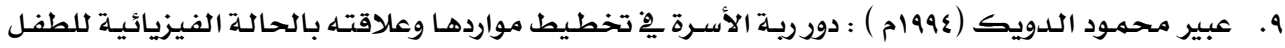

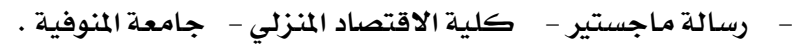

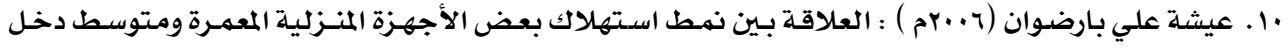

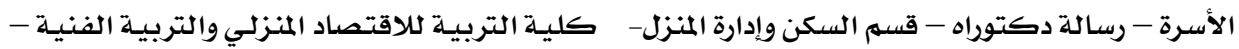

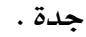

11. فاتن كمال لطفي (99vام ) : دراسة علاقة المتغيرات الاجتماعية والاقتصادية بدور الزوجة داخل أسـرتها -

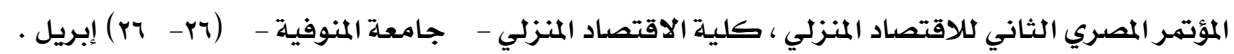

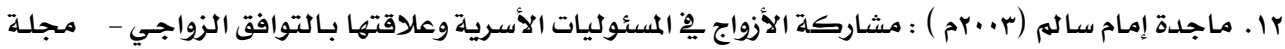

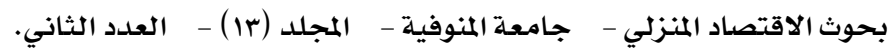

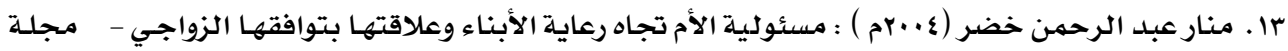

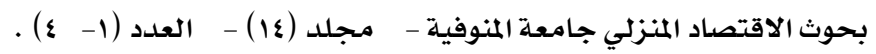

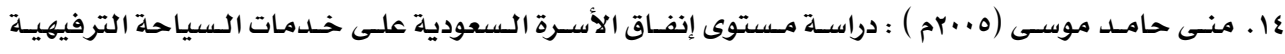

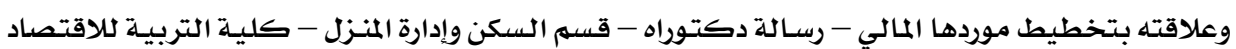
المنزلي - مكة المكرمة .

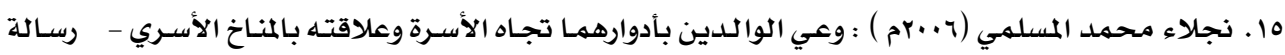
دكتوراه غير منشورة - قسم إدارة المنزل والمؤسسات - لملية الاقتصاد المنزلي جامعة المنوفية . 
17 ـ هادي مختار (199Vام) : عمل المرأة وأثره على عدم الاستمرار الأسـري ، مجلـة العلوم الاجتماعيـة - المسجلة

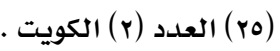

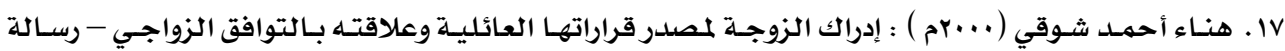

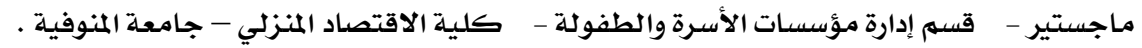

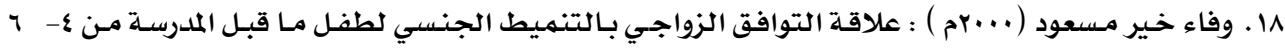

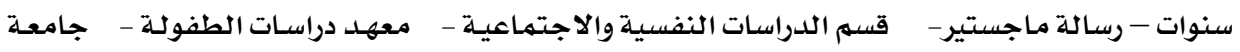

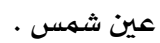

19. وفاء شلبي (999 ام ) : إدراك الزوج لـدوره يِّ المسئوليات الأسـرية وعلاقته بدافعيـة الزوجـة للإنجـاز - المجلـة

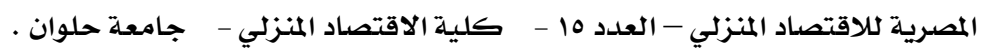

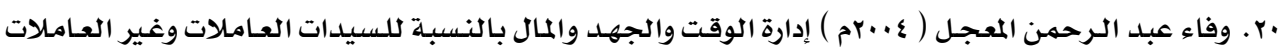

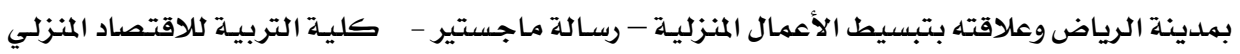
والتربية الفنية - الرياض . بماينة

21.Berter, I. F. Samson, J.W. (1987) : Family cash - flow of Dissertation, For Master's Department of Family sciences, Brigham Young University .

22. Bridges, Judith S . Souza, Am M. (1996): Black and white employed mother's role experiences . sex - roles, sep . 35 (5-6) , pp. 377- 385 . 